\title{
Spatial Regulation of Air Toxics Hot Spots
}

\author{
Rama Mohana R. Turaga, Douglas Noonan and Ann Bostrom
}

\begin{abstract}
This paper analyzes the potential implications, in terms of net social costs and distribution of risks and abatement costs, of a policy to address the problem of air toxics "hot spots." The policy we analyze involves regulation of air toxics sources at increasingly finer spatial resolutions. We develop a model of a decisionmaker choosing emission standards within a net cost minimization framework. Empirical application of the model to two counties in Florida demonstrates that regulation at finer resolutions could involve tradeoffs between net social costs and equitable distribution of risks and, in some settings, between individual and population risks.
\end{abstract}

Keywords: Hot Spots, Air Toxics, Spatial Resolution, Maximum Individual Risk, Population Risk, Net Social Costs

This is the author's manuscript of the article published in final edited form as:

Turaga, R. M. R., Noonan, D., \& Bostrom, A. (2015). Spatial Regulation of Air Toxics Hot Spots. Journal of Policy Analysis and Management, 34(2), 298-327. http://doi.org/10.1002/pam.21820 


\section{INTRODUCTION}

Equity in the distribution of environmental risks is one of the central concerns for environmental policy. Regulation of hot spots ${ }^{1}$ has emerged as one of the most debated topics in air pollution policy in the United States (U.S.) because of the concerns regarding the distribution of air pollution risk across population groups. Recent interest in hot spots could be attributed to two distinct factors: the (low) spatial resolution of air quality regulation, and emissions trading policies, which gained prominence in air pollution policy following the success of the emissions trading program for sulfur dioxide in the 1990s.

While emissions trading policies are not the focus of this study, it is worth noting two recent emissions trading policy debates in which hot spots have figured prominently: the Clean Air Mercury Rule (Graham, 2007), which was eventually set aside by the courts, and the greenhouse gas cap-and-trade program in California (Hanemann, 2008). A core argument against permit trading policies is that these programs could result in concentration of emissions (i.e., hot spots) near those plants for which it is cheaper to buy permits than to control emissions, leading not only to unequal distribution of pollution, but to the pollution burden disproportionately falling on minorities and low income groups (Burtraw, Evans, Krupnick, Palmer, \& Toth, 2005). Hot spots continue to be a major cause of opposition to emissions trading policies, although research points to no clear empirical evidence ${ }^{2}$ for distributional inequities (see Fowlie, Holland, \& Mansur,

\footnotetext{
${ }^{1}$ A national academies report defines hot spots as "locales where pollutant concentrations are substantially higher than concentrations indicated by ambient outdoor monitors located in adjacent or surrounding areas (NRC, 2004: 66).”

${ }^{2}$ Although evidence for hot spots of pollutant concentrations is sparse, one study shows that the overall damages from sulfur dioxide are likely to be higher under the pollution trading regime compared to uniform standards because of the shift in the location of pollution from rural areas (low population density) to urban areas (high population density) (Henry, Muller, \& Mendelsohn, 2011).
} 
2012 in the context of RECLAIM program and Evan J Ringquist, 2011 on the acid rain program for the most recent research on this question).

Hot spots are also of interest as a possible ramification of the spatial resolution of air quality regulation, which is the focus of this study. Air quality regulation in the U.S. has traditionally been based on compliance with National Ambient Air Quality Standards (NAAQS) at fixed ambient air quality monitors located - but distributed sparsely and unevenly - throughout the country. With the advent of new tools and techniques to measure and/or estimate ambient concentrations at finer spatial resolutions, there is a growing recognition that the current ambient monitoring network cannot adequately capture elevated concentrations at some locations, including near highways and polluting stationary sources (NRC, 2004; Levy \& Hanna, 2011). In addition, evidence in the environmental justice literature suggests that these elevated concentrations are more likely to affect minorities and low-income groups (e.g., Evan J. Ringquist, 2005; Bae, Sandlin, Bassok, \& Kim, 2007). The implication is that emission reduction strategies based on compliance with the current regulatory monitoring networks are likely inadequate to protect people living in hot spots.

The $\mathrm{NO}_{\mathrm{x}}$ standards promulgated in 2010 are an example of the regulatory response to this rising concern regarding hot spots related to the low spatial resolution of air quality regulation (“Primary National Ambient Air Quality Standards for Nitrogen Dioxide,” 75 Federal Register 26 (Feb 9, 2010), pp: 6474-6537). The new $\mathrm{NO}_{\mathrm{x}}$ standards specify 1-hour concentration standards to be met by the states, in addition to the annual average standards already in place. More importantly, the new standards require establishment of more than 160 new near-road monitoring sites, in effect increasing the spatial resolution for regulation. The focus of 40 of these sites should be on susceptible and vulnerable communities. Increasing the spatial resolution 
for regulation is likely to have implications for policy outcomes, most obviously for the distribution of air pollution risks since the policy is explicitly designed to address the distributional issue.

In this paper, we analyze the policy implications of increasing the spatial resolution of regulation. The context for our study is toxic air pollutants or air toxics ${ }^{3}$. We address two specific questions: (1) how could increasing the spatial resolution of regulation affect air toxics emission controls and social costs of regulation? and (2) what are the likely distributional consequences of regulating air toxics at finer spatial resolutions? To address these questions, we first develop a model of an optimizing decisionmaker within the context of air toxics regulation, based on a review of decision processes set forth by the US Environmental Protection Agency (EPA) and other state environmental agencies. We then apply the model to analyze the implications of regulating air toxics at finer spatial resolutions. The results of the theoretical model are demonstrated empirically by applying the model to air toxics data for Escambia and Santa Rosa counties in Florida.

The paper is organized as follows. The next section provides background on the regulation of air toxics hot spots. We then develop our decision model and analyze the results of the model. The later sections provide details of our empirical application and conclude with a discussion of the implications of our results to hot spots policy.

\section{AIR TOXICS AND HOT SPOTS REGULATION}

If the regulatory monitoring networks are deemed inadequate to regulate hot spots of criteria air pollutants such as $\mathrm{NO}_{\mathrm{x}}$, the case of air toxics is worse. The EPA regulates 188 air toxics under the Clean Air Act (CAA) and thus maintaining a large national network for monitoring so many

\footnotetext{
${ }^{3}$ Air toxics (e.g., benzene, acetylene, formaldehyde) are a class of 188 air pollutants regulated under the Clean Air Act. They are typically associated with cancer risks although exposure to air toxics can have non-cancer risks.
} 
compounds would be unviable. The National Air Toxics Trend Stations (NATTS) network has only 27 sites across the country ${ }^{4}$, monitoring approximately 100 air toxics (EPA, 2008). Recognizing the difficulties in expanding this national network, the EPA has been allocating a significant part of its air toxics monitoring budget ${ }^{5}$ on community-based air toxics projects, which are typically used to characterize air toxics concentrations at fine spatial resolutions for subsequent regulatory actions (E.P.A., 2008).

The additional feature of air toxics pollution that makes hot spots a concern is that air toxics are emitted not only from large stationary- and mobile sources, but also from a large number of smaller sources, largely unregulated, such as dry cleaners and gas stations. These sources have the potential to create localized concentrations of emissions as evidenced by the high intra-city variations in certain toxic air pollutant concentrations (Touma, Cox, \& Tikvart, 2006). This, coupled with the evidence from the environmental justice (EJ) literature that certain groups including children, low-income populations, and minorities are disproportionately exposed to these local emissions (see for example Dolinoy \& Miranda, 2004; Pastor, Morello-Frosch, \& Sadd, 2006) has contributed to the growing emphasis on air toxics hot spots.

Although California promulgated a hot spots regulation - The Air Toxics "Hot Spots" Information and Assessment Act (AB 2588) - as early as 1987, federal policy response on air toxics hot spots is more recent. Policy responses have focused primarily on characterizing and regulating air toxics at increasingly finer spatial resolutions. The EPA intended with its Urban Air Toxics Strategy (" National Air Toxics Program: The Integrated Urban Strategy," 64 Federal Register 137 (July 19, 1999), pp: 38705-740) to "characterize exposure and risk distributions”

\footnotetext{
${ }^{4}$ In comparison the State and Local Ambient Monitoring Stations (SLAMS) network had $422 \mathrm{NO}_{\mathrm{x}}$ analyzers at the end of 2007.

${ }^{5}$ EPA allocated $60 \%$ of its air toxics monitoring funding for the fiscal year 2004 to local-scale monitoring projects (E.P.A., 2004).
} 
(p: 38712) in "geographic hot spots" (p: 38712), and the Workplan for the National Air Toxics

Program and Integrated Air Toxics State/Local/Tribal Program Structure (E.P.A., 2001)

identifies addressing risks in hot spots as one of its "near-source” and

“community/neighborhood" goals.

To implement these strategies, EPA has allocated monitoring funds to local scale projects that aim to characterize the local concentration gradients of air toxics, provides guidance on local assessments of air toxics risks (E.P.A., 2006a), and is developing tools for local agencies to conduct community-scale risk assessments (e.g., E.P.A., 2006b). In 2005, EPA provided financial assistance and technical assistance to the Metro Air Pollution Control District Board of Louisville, KY to design and implement a local air toxics regulation, Strategic Toxic Air Reduction (Strategic Toxic Air Reduction Program, 2013).

It is clear that hot spots have become an important focus in air pollution policy in general and air toxics policy in particular. As noted earlier, regulation at increasingly finer spatial resolutions is evolving in response. It is not clear, however, what the likely implications are of this hot spots policy. This paper analyzes how a hot spot policy could affect the optimal emissions, social costs, and spatial distribution of risks in the context of air toxics.

\section{STUDY APPROACH}

To analyze regulation at increasingly finer spatial resolutions we first develop a model of a decisionmaker, who would use a decision rule to allocate air toxics emissions across different sources at a given spatial resolution of regulation. We use this model to theoretically analyze, $e x-$ ante, the policy outcomes of interest (e.g., optimal emission allocation and total costs) under different resolutions of regulation. We then use this theoretical analysis to answer how and why the policy outcomes would differ (or not) under a finer resolution regulation. Consistent with the policy, finer spatial resolution in our model is conceptualized as addition of new receptor 
locations to the existing set of receptors, effectively increasing the number of locations over which the air toxics sources are regulated. We then apply the model to an empirical case study air toxics emissions in two counties of Florida - to demonstrate the application of our theoretical analysis and draw implications for hot spots policy.

\section{THE MODEL}

Maximum Individual Risk (MIR), the risk to the maximally exposed individual, has been one of the major guiding criteria for EPA's regulatory decisions with regards to toxic pollutants (Adler, 2005). In the regulation of air toxics, the first step in formulating the residual risk rules involves determining an acceptable level of MIR. The EPA takes into account other factors such as abatement costs, technological feasibility, and population risks in deciding on emission controls, but only after ensuring that the MIR does not exceed an acceptable threshold value (E.P.A., 1999b). Previous research on decision making under the National Emission Standards for Hazardous Air Pollutants finds that population health benefits (measured as avoided cancer cases) influence the decision to regulate a toxic air pollutant, and costs of regulation have a statistically significant impact on the decision only if the MIR does not exceed 100 in a million (Van Van Houtven \& Cropper, 1996).

Following this understanding of EPA decision making in air toxics regulation, we model our hypothetical regulator as minimizing total social costs, subject to the constraint that the MIR does not exceed an acceptable threshold. The total social costs in our regulator's problem consist of private abatement costs to industry and population health costs. The MIR, however, is evaluated based on the estimation of risk at a fixed number of locations in space (for example, fixed air monitoring locations or the receptors of an air quality model). Hence, the constraint in

our model is that no spatial location over which risks are regulated should have an individual risk greater than a threshold standard.

Restating the regulatory choice in these terms, the decisionmaker in our model is a hypothetical regulator who chooses emission levels such that the social costs (sum of abatement 
costs to industry and population health costs from residual risk) are minimized subject to the constraint that no spatial location has an individual risk greater than a threshold value. We make several assumptions in developing our model, including: (i) the decisionmaker weights private- and population health costs equally; (ii) the value of statistical life (VSL) is constant across different population groups; (iii) abatement costs are strictly convex and increasing; (iv) only cancer risks are quantified (no non-cancer human health effects and ecological effects); (v) cancer risks are additive across pollutants; and (vi) the individuals are exposed to the estimated concentrations continuously during their entire lifetime (70 years).

\section{Decisionmaker's Problem Set-up}

Let there be $I$ sources $(i=1,2, \ldots, I)$, each of which emit $J$ toxic air pollutants $(j=1,2,3, \ldots ., J)$.

One component of our decisionmaker's objective function is the private costs of abatement borne by polluting sources. This cost is in part a function of the industrial sector, the process and abatement technologies, and the type of toxic air pollutant being abated. If source $i$ has to reduce emissions of a pollutant $j$ from a baseline of $Q^{b}{ }_{i j}(\mathrm{~g} / \mathrm{s})$ to $Q_{i j}(\mathrm{~g} / \mathrm{s})$, and if $M A C_{i j}$ represents the marginal abatement cost function for pollutant $j$ from source $i$, then the private cost of abatement can be expressed as:

$$
C_{p}=\sum_{i=1}^{I} \sum_{j=1}^{J} \int_{Q_{i j}}^{Q_{i j}^{b}} M A C_{i j}\left(q_{i j}\right) \cdot d q_{i j}
$$

The abatement costs decrease with increasing emission levels.

$$
\frac{\partial C_{p}}{\partial Q_{i j}}=-M A C_{i j}\left(Q_{i j}\right)<0
$$


The second component of the objective function is the population health costs associated with cancer risks from toxics exposure. To derive an expression for this component, we first define the individual cancer risk, which is the probability of developing cancer, $r_{m}$, as: ${ }^{6}$

$$
r_{m}=\sum_{i=1}^{I} \sum_{j=1}^{J} Q_{i j} \beta_{i j m} u_{j} \quad \text { for all individuals } m=1,2,3, \ldots, M
$$

Where,

$Q_{i j} \quad$ Emission rate (g/s) of pollutant $j$ from $i$ th source

$\beta_{i j m}$ Exposure concentration, in $\left[\left(\mu \mathrm{g} / \mathrm{m}^{3}\right) /(\mathrm{g} / \mathrm{s})\right]$, an individual $m$ is exposed to due to a unit emission rate $(1 \mathrm{~g} / \mathrm{s})$ of pollutant $j$ from source $i$

$u_{j} \quad$ Unit Risk Factor for $j$ th pollutant, $\left(\mu \mathrm{g} / \mathrm{m}^{3}\right)^{-1}$,represents the probability of cancer due to continuous lifetime exposure to $1 \mu \mathrm{g} / \mathrm{m}^{3}$ of pollutant $j$

Following the measure used by the EPA, we define population risk as the expected number of cancer cases due to exposure to toxic pollutants. For example, if one million people are each exposed to an individual cancer risk of 1 in a million (i.e., $10^{-6}$ ), one person is expected to develop cancer in that population. In other words, the population risk is the sum of all the individual risks in the population. In our set up, we have $M$ individuals in the population and hence the population cancer risk would be sum of all the $M$ individual cancer risks. In a willingness-to-pay framework, the population health costs could be estimated as the total number

\footnotetext{
${ }^{6}$ This formulation implies a linear dose-response relationship, which is a well-accepted assumption for air pollution (see Pervin, Gerdtham, \& Lyttkens, 2008; Rabl, Spadaro, \& Van Der Zwaan, 2005). Although a nonlinear doseresponse relationship is possible in principle, given the current state of knowledge the actual practice is to use a linear dose-response relationship. EPA uses linear dose-response or constant unit risk factor in a variety of risk characterization contexts, for example, in its periodic national air toxics assessment (E.P.A., 2011) and in the prospective analysis of the benefits and costs of the Clean Air Act (E.P.A., 2009).
} 
of expected additional cancer cases multiplied by the VSL $(V) .^{7}$ Thus, the population health costs can be expressed as:

$$
C_{h}=\sum_{m=1}^{M} r_{m} V
$$

Health costs are increasing in emissions because cancer risks increase with increasing emissions.

$$
\frac{\partial C_{h}}{\partial Q_{i j}}>0
$$

The constraints in the model are that the cancer risk at any of the spatial (receptor or monitoring) locations over which risks are regulated should not exceed a threshold value, $\bar{r}$. If the risks are regulated over $k=1,2, \ldots, K$ receptor locations, the constraints in the model are given by:

$$
\sum_{i=1}^{I} \sum_{j=1}^{J} Q_{i j} \beta_{i j k} u_{j} \leq \bar{r} \quad \forall k=1,2,3, \ldots, \ldots
$$

Where $\beta_{i j k}$ is the exposure concentration at any spatial location $k$.

The variable of interest for the question addressed in this research is $K$. We define spatial resolution as the number (or density) of receptor locations, within a geographic area of interest to the decisionmaker, over which risks are regulated. By our definition, the larger the number of locations, $K$, over which air pollution risks are regulated, the finer will be the spatial resolution. That is, $K$ increases with increasing spatial resolution. Larger $K$ implies more constraints in the regulator’s optimization problem. For example, regulating over smaller census units such as

\footnotetext{
${ }^{7}$ VSL is the rate of tradeoff between money and the risk of dying (Hammitt, 2000). Its application here assumes that incidence of cancer results in mortality and that VSL is constant across additional cancer cases. VSL enters as a scalar in equation (1.4), which assumes that there is no heterogeneity in willingness to pay to reduce risk of death across individuals. The constant VSL is selected for simplicity and consistency with a federal regulatory approach, yet the model is easily adapted for a distribution of VSL.
} 
blocks instead of tracts implies increasing $K$. We should note here that our model does not assume any structure for the choice of new receptor locations at the finer resolution. Although this appears arbitrary, it is not inconsistent with the real world of regulatory monitoring network design (for example, according to Su et al., 2007, the location of monitoring stations is chosen based on "qualitative criteria and personal experience" ). However, our model can be extended in future research to incorporate recent monitoring network design advances, which include methods for selecting “optimal” locations for air monitors (Kanaroglou et al., 2005; N. Kumar, 2009).

Putting everything together, the decisionmaker's problem then is:

$$
\operatorname{Min}_{Q_{i j}}\left\{\left(\sum_{i=1}^{I} \sum_{j=1}^{J} \int_{Q_{i j}}^{Q_{i j}^{b}} M A C_{i j}\left(q_{i j}\right) \cdot d q_{i j}\right)+\left(\sum_{i=1}^{I} \sum_{j=1}^{J} \sum_{m=1}^{M} Q_{i j} \beta_{i j m} u_{j} V\right)\right\}
$$

Subject to the constraints:

$$
\begin{gathered}
\sum_{i=1}^{I} \sum_{j=1}^{J} Q_{i j} \beta_{i j k} u_{j} \leq \bar{r} \quad \forall k=1,2,3, \ldots, K \\
Q_{i j} \geq 0
\end{gathered}
$$

The goal is to derive the implications of regulating at finer spatial resolutions to optimal emissions, total social costs, MIR, and population risks. The comparative statics in this case examine the effects of increasing $K$, the number of constraints at which the risk threshold binds. In order to achieve this, we first solve the model for optimal emissions at any given resolution (i.e., at any particular $K$ ) and then examine what happens to optimal emissions as we regulate at a finer spatial resolution (i.e., at any $K^{\prime}>K$ ).

\section{Optimal Emissions at a Specific Spatial Resolution (K)}

Minimizing a function $f$ is the same as maximizing $-f$. The Lagrangian is: 


$$
\begin{aligned}
& L=-\sum_{i=1}^{I} \sum_{j=1}^{J} \int_{Q_{i j}}^{Q_{i j}^{b}} M A C_{i j}\left(q_{i j}\right) \cdot d q_{i j}-\sum_{i=1}^{I} \sum_{j=1}^{J} \sum_{m=1}^{M} Q_{i j} \beta_{i j m} u_{j} V \\
& -\lambda_{1}\left(\sum_{i=1}^{I} \sum_{j=1}^{J} Q_{i j} \beta_{i j 1} u_{j}-\bar{r}\right)-\ldots .-\lambda_{K}\left(\sum_{i=1}^{I} \sum_{j=1}^{J} Q_{i j} \beta_{i j K} u_{j}-\bar{r}\right)
\end{aligned}
$$

Note how larger $K$ implies more Lagrange Multipliers, $\lambda$, and more constraints in the

\section{Lagrangian.}

Under the assumption of non-negative emissions and applying the Kuhn-Tucker conditions (see Appendix ${ }^{8}$ for full conditions), the equilibrium condition can be written as:

$$
-M A C_{i j}\left(Q_{i j}^{*}\right)+\sum_{m=1}^{M} \beta_{i j m} u_{j} V+\sum_{k=1}^{K} \lambda_{k} \beta_{i j k} u_{j}=0
$$

According to this equation, in equilibrium, the marginal abatement costs equal the marginal population health benefits plus a cost penalty that ensures no hot spots (for each pollutant-source pair $i j$ ). Solving for $Q_{i j}^{*}$ in this equation gives the optimal emissions for regulation at any spatial resolution $K$. Substituting all the $Q_{i j}^{*}$ back into the objective function gives the total social costs of regulation at any spatial resolution $K$.

\section{Optimal Emissions at Finer Spatial Resolutions $\left(K^{\prime}>K\right)$}

The question of interest is what happens to the choice of emissions and total social costs as one regulates risks at a finer resolution. That means our interest is in understanding how $Q_{i j}^{*}$ and the value of the objective function change if we add more constraints to the problem. Finer resolution here is simply the addition of new receptors (or air quality monitors) to the existing set of receptors. Let the new optimal emissions for a pollutant $j$ from source $i$ be $Q_{i j}^{\prime *}$ and the number

\footnotetext{
${ }^{8}$ All appendices are available at the end of this article as it appears in JPAM online. Go to the publisher's website and use the search engine to locate the article at http://www3.interscience.wiley.com/cgi-bin/jhome/34787
} 
of receptor locations over which the sources are regulated at the finer spatial resolution be $K^{\prime}$ (where $K^{\prime}>K$ ). As one regulates at this finer resolution, equation (1.11) becomes:

$-M A C_{i j}\left(Q_{i j}^{\prime *}\right)+\sum_{m=1}^{M} \beta_{i j m} u_{j} V+\sum_{k=1}^{K} \lambda_{k}^{\prime} \beta_{i j k} u_{j}+\sum_{k=K+1}^{K^{\prime}} \lambda_{k}^{\prime} \beta_{i j k} u_{j}=0$

Here, $\lambda_{k}^{\prime}$ is the shadow price for any receptor location $k$ under regulation at a finer spatial

resolution. Note that $\beta_{i j m}$ and $\beta_{i j k}$ are constant across resolutions because they represent the exposure concentrations from a unit emission ( $1 \mathrm{~g} / \mathrm{s})$. For a pollutant $j$ with nonnegative emissions from a source $i, Q_{i j} \geq 0$, subtracting (1.11) from (1.12) gives:

$-M A C_{i j}\left(Q_{i j}^{\prime *}\right)+M A C_{i j}\left(Q_{i j}^{*}\right)+\sum_{k=1}^{K}\left(\lambda_{k}^{\prime}-\lambda_{k}\right) \beta_{i j k} u_{j}+\sum_{k=K+1}^{K^{\prime}} \lambda_{k}^{\prime} \beta_{i j k} u_{j}=0$

\section{Implications of Spatially Finer Regulation to Optimal Emissions}

The first result of interest is the change in optimal emissions $\left(Q_{i j}^{*}\right)$ when risks are regulated at finer spatial resolutions. In equation (1.13), we have:

$$
\lambda_{k} \geq 0, \lambda_{k}^{\prime} \geq 0, \beta_{i j k}>0, u_{j}>0, M A C_{i j}\left(Q_{i j}\right)>0
$$

Given this, we can derive the following set of conditions:

$$
\begin{aligned}
& Q_{i j}^{\prime *}=Q_{i j}^{*} \text { if } \lambda_{k}^{\prime}=\lambda_{k} \forall k=1,2, \ldots, K \text { and } \lambda_{k}^{\prime}=0 \forall k=K+1, . ., K^{\prime} \\
& Q_{i j}^{\prime *}<Q_{i j}^{*} \text { if } \sum_{k=1}^{K}\left(\lambda_{k}^{\prime}-\lambda_{k}\right) \beta_{i j k}+\sum_{k=K+1}^{K^{\prime}} \lambda_{k}^{\prime} \beta_{i j k}>0 \\
& Q_{i j}^{\prime *}>Q_{i j}^{*} \text { if } \sum_{k=1}^{K}\left(\lambda_{k}^{\prime}-\lambda_{k}\right) \beta_{i j k}+\sum_{k=K+1}^{K^{\prime}} \lambda_{k}^{\prime} \beta_{i j k}<0
\end{aligned}
$$

The first interpretation of the set of equations (1.14) is that regulating at finer spatial resolutions could result in increases in optimal emissions for some sources, reductions for other sources, and no change for still other sources. It is clear from the set of conditions (1.14) that 
two parameters - the Lagrange Multiplier, $\lambda_{k}$, and exposure concentration at any location $k, \beta_{i j k}$ - affect the change in optimal emission levels.

In the problem presented here, $\lambda_{k}$ represents the change in total social costs due to a marginal change in threshold risk, $\bar{r} . \lambda_{k}$ is zero for the spatial locations $(k)$ for which the unregulated risk is below the threshold risk and is positive for locations for which the threshold risk constraint binds. Thus, if we define "hot spot" as a location at which unregulated risk, $r_{k}$, would be above the threshold risk $\bar{r}$, then $\lambda_{k}>0$ for hot spots and $\lambda_{k}=0$ for non-hot spot locations.

The second parameter, $\beta_{i j k}$, represents the exposure concentration at the $k$ th location due to a unit emission rate $(1 \mathrm{~g} / \mathrm{s})$ of pollutant $j$ from source $i$. Typically, $\beta_{i j k}$ is highest closer to the source, in the downwind direction, and decreases with distance from the source (E.P.A., 2004), which means that upwind sources closer to hot spots typically contribute more to the risk at hot spots than sources away from the hot spots.

The interpretation of $\lambda_{k}$ suggests that $\lambda_{k}$ and hence $\lambda_{k}^{\prime}$ have non-zero (and non-negative) values only at hot spots. The set of conditions (1.14) indicates that the change in optimal emissions when risks are regulated at finer spatial resolutions is a function of $\left(\lambda_{k}^{\prime}-\lambda_{k}\right)$ and $\lambda_{k}^{\prime}$, in addition to $\beta_{i j k}$. Hence, the change in optimal emissions of a pollutant $j$ from source $i$, when regulated at finer resolutions, is a function of (i) what happens to hot spots when the sources are regulated at finer resolutions and (ii) how much risk a pollutant/source combination contributes to hot spots (the value of $\beta_{i j k}$ for any $i j$ at hot spots, relative to $\beta_{i j k}$ for any other source/pollutant combination $i^{\prime} j^{\prime} \neq i j$ ) at finer resolution. Given this, it is convenient to interpret the set of 
conditions (1.14) by constructing possible scenarios for what is likely to happen to hot spots in the world of finer spatial regulation (also see Table 1). The possible scenarios are:

1. The scenario of finer spatial regulation has no hot spots that were not regulated under the world of coarse spatial resolution

2. Finer spatial regulation results in the regulation of some hot spot locations that were not regulated under the coarse resolution

Under scenario $1, \lambda_{k}^{\prime}=0 \forall k=K+1, . ., K^{\prime}$ and $\lambda_{k}^{\prime}=\lambda_{k} \forall k=1,2, \ldots, K$. This means that the optimal emissions do not change for any source/pollutant combination, $i j$. Under scenario 2, for the source/pollutant combinations (ij) that contribute most (high $\beta_{i j k}$ relative to other source/pollutant combinations) to hot spots captured at finer resolution, optimal emissions will

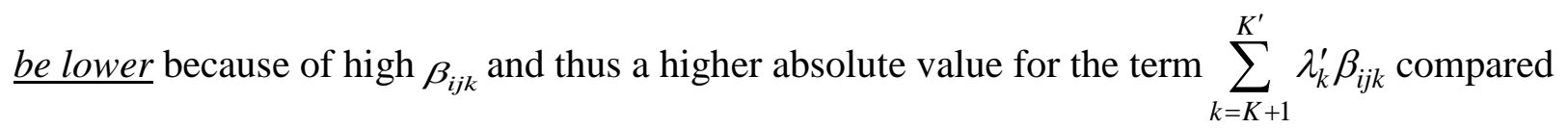
to the term $\sum_{k=1}^{K}\left(\lambda_{k}^{\prime}-\lambda_{k}\right) \beta_{i j k}{ }^{9}$ in (1.14). For sources that contribute relatively little to hot spots (typically those sources that are distant from hot spots captured at finer resolution), $\beta_{i j k}$ tends to be low. If $\lambda_{k}^{\prime 10}$ is sufficiently lower than $\lambda_{k}$ for hot spots captured at the coarser resolution so as to make the absolute value of the term $\sum_{k=1}^{K}\left(\lambda_{k}^{\prime}-\lambda_{k}\right) \beta_{i j k}$ greater than the term $\sum_{k=K+1}^{K^{\prime}} \lambda_{k}^{\prime} \beta_{i j k}$, then the optimal emissions will be higher for those sources when risks are regulated at a finer spatial resolution. Intuitively, optimal emissions could be higher at finer spatial regulation for sources distant from hot spots, because (i) the reduction in optimal emissions, for sources responsible for hot spots, creates slackness in constraints at non-hot spot locations and (ii) because of this

\footnotetext{
${ }^{9}$ Note that $\lambda_{k}^{\prime} \leq \lambda_{k} \forall k=1,2, \ldots, K$ and hence this term is always non-positive.

${ }^{10} \lambda_{k}^{\prime}=0$ for receptor locations that do not remain as hot spots under regulation at finer resolution
} 
slackness, the increase in costs (due to emission reductions by sources responsible for hot spots) could be offset by higher emissions for other sources that do not contribute to hot spots captured at finer resolution.

In summary, the set of conditions (1.14) indicate that (i) spatial resolution of regulation does not matter to optimal emissions when finer spatial resolution does not capture new hot spots that were not regulated under coarse resolution, (ii) optimal emissions will be lower (i.e., stricter standards) for sources that contribute most to new hot spots regulated under finer spatial resolution, and (iii) optimal emissions could be higher (i.e., laxer standards) for sources that do not contribute significantly to new hot spots regulated at finer resolution.

\section{Implications for Total social Costs}

Total social costs are non-decreasing when emissions are regulated at finer resolution. This comes from a standard result in optimization theory that the value function is non-decreasing with the addition of constraints to the problem. Table 1 summarizes the model predictions.

\section{[TABLE 1 HERE]}

\section{Implications for MIR and Population Risk}

Our model suggests that under a scenario where finer regulation does not reveal new hot spots, the optimal emissions would remain unchanged and thus the MIR and population risk will be the same across the two resolutions.

However, if finer regulation does reveal new hot spots, according to our model, the optimal emissions for any given source could be higher or lower under finer regulation. Accordingly, our theory alone cannot predict whether the maximum individual risk would be higher or lower under a finer regulation. The same logic applies to population risks as well: they could be lower or higher under finer regulation. 
These results, that the MIR and population risk could be higher or lower under finer regulation relative to a coarse regulation, suggest an important implication for policymakers: In regulating hot spots, it is theoretically possible to have a tradeoff between MIR and population risk. That is, it is possible to have a lower MIR but higher population risks at finer regulation, relative to the coarse regulation.

\section{EMPIRICAL APPLICATION}

The site for our empirical application is a two-county (Escambia and Santa Rosa) region in Pensacola, FL. The total population of the two counties according to the 2000 census is over 400,000 with a little over 22 percent non-white population. According to the toxics release inventory (TRI) data for 2009, Escambia county was at the top among all Florida counties with over 30 million pounds of toxics emissions. ${ }^{11}$ In response to the local environmental concerns, The US Congress, through the EPA Region IV and the Centers for Disease Control, sponsored a large-scale research project, the Partnership for Environmental Research and Community Health (PERCH), to conduct a comprehensive study on environmental impacts in the region, including an assessment of risks from toxic air pollutants in the two-county region (UWF, 2011). Our study is part of this PERCH project. Community concerns about toxic contamination and the associated environmental justice issues combined with the current focus of environmental agencies on this region's environmental health problems provide a suitable setting to demonstrate the application of our theoretical model and analyze the impacts of potential hot spot regulations.

According to the National Toxics Inventory (NTI) of 1999, the two-county study area had 94 air toxics emission sources distributed across 43 facilities including manufacturing, utility plants,

\footnotetext{
${ }^{11}$ Source: EPA TRI Explorer Florida State Fact Sheet, available at http://www.epa.gov/cgibin/broker?view=STCO\&trilib=TRIQ1\&state=12\&SFS=YES\&year=2009\&_service=oiaa\&_program=xp_tri.sasma cr.tristart.macro
} 
and waste landfills. These sources emitted 78 different air toxics. Although some of the major facilities are regulated under the federal maximum achievable control technology (MACT) standards, to our knowledge, the facilities in this region are not subject to any state or local air toxics regulations. This provides us with an opportunity to analyze the ex ante implications of a spatially fine regulation at the local level.

Our research uses a subset of the 94 sources, selected based on the following two criteria: (i) the source is categorized as a "major" 12 source according to the Clean Air Act and (ii) the source emits at least one toxic air pollutant for which inhalation cancer risk can be quantified. Applying these two criteria, the final sample (see Table 2) includes 15 emission sources from seven facilities that emit six different air toxics. ${ }^{13}$

The empirical application uses three spatial resolutions: census tract, census block group, and census block. The census tract ("tract" from hereon) is the biggest spatial unit and is composed of several census block groups (“block group” from hereon). The census block (“block” from hereon) represents the finest spatial unit with a number of blocks forming a block group. The fact that population data and other demographic data of the US Census Bureau are available at these three resolutions makes the empirical application of the model feasible. In our study site, there are 77 census tracts, 319 block groups, and 9881 blocks. We assume that the regulation at any spatial resolution is based on the pollutant concentrations estimated at the centroid of the relevant census unit. For example, for tract level regulation, the receptors or monitors are assumed to be located at the centroid of the census tract.

\footnotetext{
${ }^{12}$ According to this definition, a "major" source of hazardous air pollutants (HAP) is one that emits more than 10 tons per year (TPY) of any one of the regulated HAPs or more than 25 TPY of a combination of HAPs.

${ }^{13}$ It turned out that one of the eight facilities that meet our criteria was not regulated under any MACT although it was classified as a "major" source. This facility was dropped out of the final sample because no abatement cost information was available for the sources within this facility.
} 
Given the available spatial resolutions, several analytical choices have been made. First, the estimated risk at the geographical centroid of a census unit was assumed to represent the risk to any individual within that census unit. ${ }^{14}$ Second, regulation at finer resolution assumed to include regulation of risks both at the existing locations (i.e., locations over which risks would be regulated at coarser resolution) and the new locations (i.e., the additional locations over which risks are regulated at the finer spatial resolution).

\section{Data}

\section{Marginal Abatement Cost (MAC) Functions}

We are limited by the lack of availability of appropriate data in estimating the marginal cost functions. We explored three possible approaches to estimating MAC functions. One approach, the production cost approach, requires detailed firm-level information on input quantities and abatement volumes (e.g., Carlson, Burtraw, Cropper, \& Palmer, 2000; Rezek \& Blair, 2005). The second approach, econometric estimation using direct costs of abatement, is useful when firmlevel data on abatement costs and abatement volumes are available for a large sample of firms (e.g., Hartman, Wheeler, \& Singh, 1997). The pollution abatement cost expenditure (PACE) data collected by Census Bureau are an example of such data. However, these data do not have sufficient information on the abatement costs for toxic air pollutants.

We chose a third approach, the engineering cost approach to estimate MAC functions (e.g., Kilmont, Amann, \& Cofala, 2000; E.P.A., 2003; Karvosenoja \& Johansson, 2003; Rousseau \& Proost, 2005). This approach requires, for each source in our sample, data on available emission control options, emission reductions associated with each technology, and the annual costs of implementing the technology. In an ideal case, these data should be specific to the source in our

\footnotetext{
${ }^{14}$ Based on this assumption, for estimating the population risk we weighted the risk at the block centroid (the block being the finest unit at which population data are available) by the population of the block and aggregated over all the blocks.
} 
sample. However, it is difficult, if not impossible, to collect source-specific abatement cost data. Thus, we estimate MAC functions based on secondary data obtained from Regulatory Impact Analyses (RIA) and background information documents that EPA developed to assess the cost impacts of its MACT standards. We outline below the steps involved in and the limitations of our approach.

In the first step, we use air permit documents available from the Florida Department of Environmental Protection to identify the seven industrial processes (see column 2 of Table 2) that correspond to the 15 sources in our sample. Then we identify the MACT standards under which these industrial processes are regulated.

In the next step, we mine the RIAs and background information documents related to the MACT regulation of each industrial process for uncontrolled emission rates, emission control technology options, emission reductions corresponding to the application of each technology option, and the annual costs of the technology. Using this information, we estimate the emissions remaining after the application of each technology or in other words, emission rates $\left(Q_{i j}\right)$. This allows us to estimate the MACs as a function of emission rates, which is consistent with the MAC specification in the theoretical model. Based on previous literature (Mariam \& Barre, 1996), we use an exponential function to fit our cost functions. Note that the data points in the regression are the abatement technology options available for each of the industrial processes that represent our sources. We fit the following function using non-linear least square regression separately for each of the seven industrial processes.

$$
C_{x y}=a_{x} e^{b_{x} Q_{x y}}+\varepsilon_{x y}
$$


$C_{x y}=$ Annual costs of abatement for abatement option $y$ in industrial process $x(\$)$

$Q_{x y}=$ Emission rate after application of abatement option $y$ in industrial process $x$ (Ton/Year)

$a_{x}, b_{x}=$ Parameters to be estimated

$\varepsilon_{x y}=$ Error term

We assign the parameters $a_{x}$ and $b_{x}$ obtained from the regressions fitted using equation 1.15 to the 15 sources that correspond to these seven industrial processes to obtain $a_{i}$ and $b_{i}$ for each source $i$. Further, since we do not have the data for each pollutant $(j)$, we assign the same parameter to each of the pollutants $(j)$ emitted from each source (i) to obtain $a_{i j}$ and $b_{i j}$ required for our empirical application of the theoretical model.

We must note two major limitations of approach to estimation of cost functions. First, typically, the RIAs report cost estimates at an aggregated industrial process level; however, they also report the number of sources on which these aggregate estimates are based. We use this information to obtain cost estimates for an "average" industrial process, calculated as the total annual costs of applying a given abatement technology divided by the number of regulated sources on which the aggregate estimates are based. The assumption then in the estimation of our MAC functions is that the source in our analysis represents an "average” industrial process.

Second, in almost all RIAs, the abatement technology options identified are not specific to abatement of any single toxic air pollutant; rather the technology abates a group of pollutants and there is no information in the RIAs on the removal efficiency of individual pollutants. Thus, in this analysis, the cost function developed for a given source is applied separately to all the pollutants emitted from that source. The implication of this is that the costs to industry are potentially counted multiple times, once for each pollutant that a particular control technology abates. This is a limitation of this approach to estimating MAC functions. The estimated cost 
parameters are given in Table 2. As shown in the table, the cost estimates are relatively crude with some of the estimates being fitted based on just two abatement technologies $(n=2)$.

\section{[TABLE 2 HERE]}

\section{Estimation of Exposure Concentrations $\left(\beta_{i j m}\right)$}

Our empirical application uses an integrated assessment tool, the Regional Air Impact Modeling Initiative (RAIMI), to model the exposure concentrations for airborne toxics. RAIMI integrates an air pollution fate-transport model with a risk model to predict cancer risks from exposure to air toxics. Annual average ambient air toxics concentrations are estimated using the version 3 of the Industrial Source Complex Short Term (ISCST3) ${ }^{15}$ air dispersion model integrated within RAIMI. ISCST3 is an air pollution fate-transport model, which can predict ambient concentrations of air pollutants from point sources at specific location in space. Ambient air toxics concentrations are used as surrogates for exposure concentrations because RAIMI does not incorporate an exposure model. ${ }^{16}$

ISCST3 requires many inputs for estimating the ambient concentrations, including (a) meteorological data such as wind speed, wind direction, and vertical temperature profiles, (b) emission characteristics such as stack height and stack temperature, and (c) land use data. We use EPA’s Meteorological Preprocessor for Regulatory Models (MPRM) to obtain meteorological data collected at the Pensacola Regional Airport for the years 1986 to 1990 . We

\footnotetext{
${ }^{15}$ ISCST3 is a steady-state, multiple source, Gaussian dispersion model and has been the preferred regulatory model for industrial sources until it was replaced by AMS/EPA Regulatory Model (AERMOD) in 2005 (70 FR 68217, November 9, 2005). The literature on the evaluation of ISCST's ability to predict the concentrations measured by fixed monitors shows an acceptable level of accuracy (see for e.g., A. Kumar, Bellam, \& Sud, 1999; Lorber, Eschenroeder, \& Robinson, 2000; Sivacoumar, Bhanarkar, Goyal, Gadkari, \& Aggarwal, 2001; Pratt et al., 2004).

${ }^{16}$ Ambient air pollution concentrations only tell us the concentrations of pollutants in the air. The concentrations to which individuals are actually exposed (i.e., exposure concentrations) depend not only on the ambient concentrations but also on factors such as the duration of exposure, human activity patterns (for example, exercising vs. sitting), and whether the individuals are indoor or outdoor at the time of exposure.
} 
collected emission characteristics for the selected sources from NTI of 1999 and land use data from U.S. Geological Service.

\section{Value of Statistical Life}

Given that there are numerous estimates of VSL, EPA and other regulatory agencies utilize values from meta-analyses in their benefit cost assessments. EPA used a mean VSL of \$4.8 million (in $1990 \$$ or 5.5 million in $1999 \$$ ) with a standard deviation of $\$ 3.2$ million in its benefit cost assessment of the Clean Air Act (E.P.A., 1999a) for 1990-2010. Our analysis assumes the same VSL (\$5.5 million in 1999\$). ${ }^{17}$

Baseline Emissions: The baseline emissions represent current emissions according to the 1999 NTI for the sources selected for the empirical application.

Unit Cancer Risk Factors: Values of unit risk factors, $u_{j}$, for each of the six pollutants in the sample are from EPA’s Integrated Risk Information System database (E.P.A., 2013). The values used in the analysis are: 0.0000078 for benzene, 0.0000022 for acetaldehyde, 0.000013 for formaldehyde, 0.000068 for acrylonitrile, 0.00024 for nickel, and 0.0043 for arsenic.

Population Data: The 2001 population data are obtained from the US Census Bureau.

\section{ANALYSIS AND RESULTS}

The first step in our analysis requires estimating the optimal emissions $\left(Q_{i j}\right)$ for each pollutant $(j)$ from each source (i) included in our empirical application. We use General Algebraic Modeling System (GAMS) (www.gams.com) version 22.3, with CONOPT as the non-linear programming solver, to estimate the optimal emissions. GAMS searches for emissions $\left(Q_{i j}\right)$ that satisfy the set of equations $1.7,1.8$, and 1.9. GAMS uses as inputs the various parameters described in the data section, such as exposure concentrations at the receptor locations for each spatial resolution, unit

\footnotetext{
${ }^{17}$ We conducted our analysis for other available VSL estimates (\$2.04 million estimate by Mrozek \& Taylor (2002) and the $\$ 7.35$ million estimate by Viscusi \& Aldy (2003) and found our results to be insensitive to VSL.
} 
risk factors, baseline emissions, parameters of the marginal abatement cost functions (as estimated in Table 2), and the value of the threshold risk standard. We use the optimal emissions estimated by GAMS at each spatial resolution to calculate our other outcomes of interest, such as total social costs, individual risks, and population risks.

\section{Optimal Emissions}

The optimal emissions based on the decision model developed in the previous sections are estimated at a cancer risk threshold of 100 in a million. ${ }^{18}$ This value is the MIR that EPA aims to achieve under its residual risk regulation (E.P.A., 1999).

Table 3 shows the baseline and optimal emissions at tract, block group, and block resolutions for each of the 34 source/pollutant combinations. First, the optimal emissions at the block group regulation are identical to those at the tract regulation. Second, if the sources are regulated at the finer block resolution instead of the block group resolution, the optimal emissions are higher for a number of sources (for example, all pollutants and sources from GP) and lower for some sources (for example, acetaldehyde from IP02). ${ }^{19}$

\section{[TABLE 3 HERE]}

Table 4a shows the optimal emissions of acetaldehyde (except for the source SF01 for which the pollutant is acrylonitrile) from a set of select sources when risks are regulated at two different resolutions: tract and a finer block group resolution. This first column in Table 4a shows the location of hot spots ( $k$ for which $\lambda_{k} \neq 0$ ), the second column shows the shadow price $\left(\lambda_{k}\right)$ for hot spots at tract resolution, and the third column shows the shadow price $\left(\lambda_{k}^{\prime}\right)$ for hot spots at the

\footnotetext{
${ }^{18}$ We also estimated the optimal emissions at two other risk thresholds: 10 in a million and 1 in a million. The results at these risk thresholds are consistent with the results at 100 in a million threshold and are available from the authors on request.

${ }^{19}$ From Table 3, we can also note that the optimal emissions for some sources (e.g., acetaldehyde from IP01 and formaldehyde from FG01) deviate significantly from the baseline emissions. This deviation indicates that at 100 in a million risk threshold, the current emissions are too far away from the optimal. It also reflects perhaps the crudeness of our abatement cost estimates.
} 
finer block group resolution. The last column in Table 4a shows the exposure concentrations due to a unit emission rate $\left(\beta_{i j k}\right)$ at hot spots for the select sources.

It can be observed from Table 4a that the regulation at finer resolution does not capture any new hot spots that were not regulated at tract resolution. Location numbers 16 and 17 are the hot spots at both block group resolution and tract resolution. Consistent with the interpretations of the conditions (1.14), the optimal emissions are the same at both spatial resolutions.

Table 4b shows the results for regulation at block group resolution and at a finer block resolution. Regulation at the finer block resolution results in the regulation of two new hot spots, at location numbers 2503 and 9361 (grey-shaded rows in Table 4b). The values of $\beta_{i j k}$ for the sources indicate that SF01 has the maximum value $\left(6.41 \mu \mathrm{g} / \mathrm{m}^{3}\right.$, the cell in bold in Table $\left.4 \mathrm{~b}\right)$ at the hot spot 2503, much more than for any other source, and thus contributes most to the risk at that hot spot. Accordingly, the optimal emissions for this source are much lower (0.03 TPY) under a finer block resolution, relative to $0.11 \mathrm{TPY}$ at block group resolution. Similarly, the source IP02 has the highest exposure concentration $\left(0.5218 \mu \mathrm{g} / \mathrm{m}^{3}\right.$, an order of magnitude higher than the next highest source SO01, which is also in bold in Table 4b) at hot spot location 9361 and thus the optimal emissions of acetaldehyde would be $69 \mathrm{TPY}$ at the finer resolution, much lower than 135 TPY at block group resolution. All the other sources contribute insignificant risk to hot spots at finer resolution and thus their optimal emissions for these sources are higher at the finer resolution. Again, this is consistent with the interpretation of the conditions (1.14).

Intuitively, the results here can be summarized in the following way. When the regulation of air pollution is based on compliance at only a few locations (i.e., low spatial resolution), it is likely that there will be other locations where the risk exceeds the desired standards (i.e., hot spots) and the sources that contribute to these hot spots are subject to laxer controls than they 
would otherwise be. These under-regulated sources would be subject to stricter controls under finer spatial regulation, if spatial locations are added in such a way that hot spots that are previously under-regulated are now included in the set of locations used for assessing compliance with risk threshold standards. Further, under the finer regulation, a cost-minimizing framework could result in higher optimal emissions (or lower controls) for some sources, to the extent that these emissions have not increased enough to violate the risk threshold standards at any location at the finer resolution regulation. This emissions increase at some sources follows because some other sources' emissions were curtailed (to squelch the new hot spots). This relieves pressure on the threshold risk constraint at other affected monitors, thereby opening up the possibility for other nearby sources to emit higher amounts (i.e., abate less) while still remaining under the threshold at those monitors.

\section{[TABLES 4a and 4b HERE]}

\section{Net Costs}

Our theoretical analysis suggests that total social costs should be non-decreasing with spatial resolution. The empirical results are consistent with that result. Because the optimal emissions are the same for regulation at the tract and at the block group resolutions, the total social costs are also the same at these two resolutions. However, the regulation at the block resolution results in costs twice as high as those at the other resolutions (\$35.5 million at block resolution as opposed to $\$ 17.8$ million at block group and tract resolutions). This is because, at the block resolution, although the optimal emissions are marginally higher (compared to other resolutions) for a number of sources, there is a significant reduction in optimal emissions for two sources: IP02 and SF01. The abatement costs for these two sources together account for about 60 percent of additional net costs. Figure 1 shows the variation of total social costs, abatement costs, and 
population health costs with spatial resolution when risks are regulated at different threshold risk values.

\section{[FIGURE 1 HERE]}

\section{Spatial Distribution of Cancer Risks}

The main goal of regulating air toxics risks at finer spatial resolutions is to address disproportionate impacts of air toxics exposures. It is expected that by regulating risks at finer spatial resolutions, risks in hot spots that are not apparent at coarse resolution could be reduced, thus ensuring a more equitable distribution of risk.

\section{Maximum Individual Risk (MIR)}

In order to demonstrate the potential impact of regulation at finer resolution on spatial distribution of risks, the analysis presented in this section estimates cancer risks at two resolutions of regulation -tract and block ${ }^{20}$ - and at two threshold risk levels (100 in a million and 10 in a million). We estimate cancer risk distribution under the tract and block regulation, by first obtaining the optimal emissions that the decisionmaker would choose under the two resolutions of regulation. We then use the set of optimal emissions under each regulation to estimate block-level cancer risks, which produces the distribution of cancer risks under the two resolutions of regulation.

Figure 2 shows the spatial distribution of cancer risks for tract and block resolutions of regulation, at the risk threshold of 100 in a million. Most of the region has an estimated individual cancer risk of less than 10 in a million at both resolutions. If the risks were to be regulated at the tract resolution, the MIR would be 187 in a million. In other words, the cancer risk faced by the individuals in the census block that is subjected to the maximum risk is 187 in a

\footnotetext{
${ }^{20}$ Optimal emissions were also estimated for regulation at block group resolution. However, the analysis is restricted to tract and block level resolution because there was very little variation in optimal emissions between tract and block group level resolutions at all risk thresholds.
} 
million, when the regulation of sources is based on the constraint that the risk in no census tract should exceed 100 in a million risk. Figure 2 also shows that the MIR under the finer block regulation would be 100 in a million. Figure 3 magnifies the region where the individual cancer risk would exceed 100 in a million in some blocks, if the sources were to be regulated at a tract resolution. Shaded blocks show hot spots where individual risk exceeds 100 in a million.

Figures 4 shows the spatial distribution of individual cancer risk under tract and block resolutions, when the risk threshold for regulation is 10 in a million. Had the risks been regulated at the coarser tract regulation, the MIR would have been 17 in a million instead of the threshold standard of 10 in a million, which is the MIR under the finer regulation at the block level. Figure 5 magnifies the region in which some locations have an individual cancer risk in excess of the 10 in a million threshold.

Thus the analysis of the spatial distribution of individual cancer risks shows that finer resolution regulation would prevent some hot spots that would not have been apparent under coarser regulation.

\section{[FIGURE 2 AND FIGURE 3 HERE]}

\section{Population Risks}

The population risk is the residual risk remaining after the regulation and is expressed here in terms of the number of expected additional cancer cases due to residual risks. At the 10 in a million and 1 in a million risk thresholds, the population risks would be lower under finer resolution regulation.

An important result of our analysis is that at the 100 in a million threshold, the population risks are higher when risks are regulated at the finer block resolution (0.00244 additional expected cancer cases at the block regulation vs. 0.00215 at the coarser tract regulation). In the 
context of our model, one can explain this result as follows. Results in the previous sections show that, under the regulation at finer resolutions, optimal emissions would have to be lower for those sources that contribute significantly to the hot spots. That is, the emission controls at these sources under block resolution would be much stricter relative to the regulation at the tract resolution. Stricter controls at these sources mean higher abatement costs and lower risks at hot spots under the finer block regulation. The stricter controls at these sources would not only make the risks at hot spots lower but simultaneously result in lower risks at some non-hot spot locations because in our model every source imposes some level of risk at every spatial location. Under the finer resolution, this lowering of risks at non-hot spot locations allows our decisionmaker, who is minimizing the overall social costs, to have higher emissions for the sources that contribute risk to these locations If the increase in emissions from these other sources increases risk in areas that are highly populated, then the overall population risks might increase when risks are regulated at finer resolutions.

Our analysis of the changes in the population risks across the study area shows that at the 100 in a million threshold risk, where we find higher population risk at finer regulation, 93 percent of the population in the study area would experience higher risks (18 percent higher) at finer regulation and only 7 percent would be subject to lower risks (14 percent lower). The overall increases in population risks are driven by significant reductions to a few and small increases to a large proportion of the population in the study area.

The results of our analysis thus suggest that while regulation at finer resolution (block) might result in a lower MIR, as shown in the previous section, population risk would be higher. While this result might be specific to the empirical context studied here, the results suggest more 
generally that reductions in individual risks could come at the cost of increases in overall population risks under some conditions.

\section{Distribution of Abatement Costs}

The empirical results for Escambia and Santa Rosa Counties show that optimal emissions decrease for some sources of air toxics, increase for some, and remain unchanged for others as the spatial resolution of regulation increases from tract to block resolution, for the net cost minimizing decisionmaker. The changes in optimal emissions at finer resolutions are associated with changes in abatement costs for regulated sources. Using the cost functions estimated for the empirical application, the changes in abatement costs corresponding to a change in optimal emissions at finer spatial resolution are calculated. Table 5 shows the percent change in abatement costs due to regulation at the block resolution, relative to tract regulation. Because the cost functions are assumed identical for every pollutant emitted from a source, the changes in costs in the table reflect the cumulative costs of abatement of all pollutants from a source.

The results at 100 in a million threshold risk suggest that significant abatement costs would be imposed on two facilities or four sources when risks are regulated at block resolution instead of a coarser tract resolution. Abatement costs would drop for all the other sources. At the other risk thresholds, however, costs would increase for all sources except one. Note that the zeros in the table reflect either unchanged non-zero levels of optimal emissions or zero emissions at both the coarse resolution and the finer resolution. As expected, regulation at finer resolution not only affects the distribution of cancer risks, it also affects the distribution of abatement costs.

\section{[TABLE 5 HERE]}

\section{DISCUSSION AND CONCLUSIONS}


Hot spots of air pollution have emerged as an important topic because of the concern that some population groups are disproportionately subject to higher air pollution risks than others. In this paper, we have analyzed an emerging policy response to deal with hot spots - increasing the spatial resolution over which air pollution risks are regulated. Consistent with recent policy developments (e.g., new $\mathrm{NO}_{\mathrm{x}}$ standards), we conceptualized finer spatial resolution regulation as an addition of new receptors over which risks are regulated. The analysis shows that such policies have the potential to address equity concerns, if the spatial resolution is increased in such a way that regulation at the finer resolution captures hot spots that would be unregulated under a coarser resolution.

The results of our study have two main implications for the policy of high spatial resolution regulation. First, as expected, total social costs (the sum of private abatement costs and population health costs) would be higher under the finer spatial regulation. In our empirical application of two counties in Florida, the costs at the finer block resolution approach twice the social costs at the coarser tract resolution. On the other hand, finer spatial regulation would result in a more equitable distribution of risk by reducing individual risk in the hot spots that would go unregulated under coarser resolutions. This tradeoff between the social costs of regulation and protecting the maximally exposed individual would be largely consistent with the air pollution policy in the U.S. in general and air toxics regulation in particular (Van Houtven \& Cropper, 1996).

Second and the more striking result of our analysis, however, is the potential tradeoff between individual risks and population risks. In the two-county area we studied, while the MIR would be lower under the regulation at the finer census block resolution, the population risks, measured as the expected number of cancer cases, would be higher. That is, it is possible that while protecting 
a few individuals from high risks, the policy would impose a larger aggregate risk on the population.

Our results demonstrate the potentially perverse outcomes of hot-spot policies targeting equity, adding empirical weight to the ethical critiques of MIR as a basis for policy (see Adler, 2005), and economic and public health critiques of policies that ignore the population in preference to individuals. For public health experts, ignoring the population in preference to individuals is contrary to the historically accepted basis for public health decision making (Goldstein, 1995). From an economic efficiency perspective, reducing small individual risks for large populations is likely to lead to greater benefits than reducing large individual risks for smaller populations (Kopp, Krupnick, \& Toman, 1997; Hamilton \& Viscusi, 1999).

While equity is a legitimate and important goal for environmental policy, our results show that policies addressing equity issues should be carefully analyzed before implementation. It is not so simple, generally, as thinking that eliminating hot spots will improve environmental justice or that more monitors will improve population risk. Our model shows the reverse might be true, and ultimately these are empirical questions. This further implies that one-size-fits-all regulatory approaches to hot spots might have mixed results across local contexts. Much of air pollution policy resembles squeezing a balloon, where regulatory pressure and tighter controls in one area will displace pollution to other areas. Hot spots policy should anticipate this in its design, especially with an eye to equity across population groups.

Future extensions to this work could take at least a couple of directions. First, incorporating formal uncertainty analysis in regulatory decision making has been an increasing emphasis at EPA. Recent National Academies reports commissioned by EPA emphasize the importance of more explicit recognition of uncertainty in health risk estimates as well as economic and 
technological factors in regulatory decision making (Institute of Medicine, 2013; National Research Council, 2014). Future work could incorporate the parameter uncertainty in our regulatory model to test, for example, if the optimal emissions differ between coarse and finer regulation, even after accounting for uncertainty in model parameters such as ambient air concentrations and unit risk factors.

Second, although our study is within the context of toxic air pollutants, our approach can be extended to criteria pollutants as well. The $2010 \mathrm{NO}_{\mathrm{x}}$ rules ("Primary National Ambient Air Quality Standards for Nitrogen Dioxide,” 75 Federal Register 26 (Feb 9, 2010), pp: 6474-6537), which require a number of additional monitors to assess NAAQS compliance, is a clear example of increasing spatial resolution for regulation of criteria air pollutants. Future work could use our approach to study the implications of increasing spatial resolution of regulation for the case of criteria pollutants or other type of pollution. In this context, it is important to note that we assume a linear dose-response function, consistent with the current practice for modeling damage from air toxics. However, future studies could model damage from air pollution to be nonlinear in emissions, wherever appropriate, potentially making hot-spot policies more efficient than we find in this study.

Finally, our study raises the interesting issue of identifying an appropriate or optimal spatial resolution of regulation. Our study shows that increasing the spatial resolution of regulation involves a classic efficiency-equity tradeoff: increasing the resolution has equity benefits in terms of reducing hot spots but it is always going to cost more socially. Policy design must strike a balance. It may not be acceptable to increase the costs infinitely to create a perfectly equitable world of no hot spots. The policymaker must still choose a resolution of regulation that has an “acceptable” tradeoff. Our study does not model the policy designer’s choice of spatial 
resolution. It does highlight a tradeoff between increasing the spatial resolution of regulation (and eliminating hot spots) and increasing abatement (and even population health) costs. We leave the question of optimal spatial resolution and threshold risk standard, jointly determined with optimal emissions as modeled here, to a broader policy design analysis. To inform optimal spatial resolution of regulation, future work could develop a way to incorporate both the equity benefits and the social costs of reducing hot spots, including costs of additional monitoring, in the policymaker's objective function.

\section{Acknowledgments}

We gratefully acknowledge research support from the University of West Florida (UWF) Sub Award \# 2519-229-22(02). The prime award is from the U.S. EPA (Award \#/x974550002-3) for the Partnership for Environmental Research and Community Health (PERCH) project. We would also like to acknowledge three anonymous reviewers and the editor of this journal for their valuable inputs to the manuscript. 
Table 1. Model Predictions for Optimal Emissions and Net Social Costs under Regulation at Finer Resolution

\begin{tabular}{ccc}
\hline $\begin{array}{l}\text { Risk contribution of } i j, \\
\text { relative to all } i^{\prime} j^{\prime} \neq i j \text {, to hot } \\
\text { spots at finer resolution }\end{array}$ & New hot spots at finer resolution? \\
\hline High & $Q_{i j}^{* \prime} \downarrow$ & No \\
& $N C^{\prime} \uparrow$ & $Q_{i j}^{* \prime} \leftrightarrow$ \\
& $N C^{\prime} \leftrightarrow$ \\
Low & $Q_{i j}^{* \prime} \downarrow \uparrow \leftrightarrow$ \\
& $N C^{\prime} \uparrow \leftrightarrow$ & $Q_{i j}^{* \prime} \leftrightarrow$ \\
& $N C^{\prime} \leftrightarrow$ \\
\hline
\end{tabular}


Table 2 Sources, Pollutants, and the Parameter Estimates of their Cost Functions

\begin{tabular}{|c|c|c|c|c|c|}
\hline \multirow[t]{2}{*}{ Facility type } & \multirow{2}{*}{$\begin{array}{l}\text { Source (ID) } \\
\text { (i) }\end{array}$} & \multirow{2}{*}{$\begin{array}{l}\text { Pollutants } \\
\text { modeled }(j)\end{array}$} & \multicolumn{2}{|c|}{ Parameter estimates* } & \multirow[b]{2}{*}{$\mathbf{R}^{2}$} \\
\hline & & & $a_{i j}$ & $b_{i j}$ & \\
\hline \multirow[t]{2}{*}{ Paper Manufacturing } & $\begin{array}{l}\text { Bleaching Line Vent } \\
\text { (IP01) }\end{array}$ & Acetaldehyde & $\begin{array}{c}5303579 \\
(1230) \\
\end{array}$ & $\begin{array}{c}-0.019 \\
(0.000014)\end{array}$ & $\begin{array}{l}100 \% \\
(n=3)\end{array}$ \\
\hline & $\begin{array}{l}\text { Pulping System Vent } \\
\text { (IP02) }\end{array}$ & $\begin{array}{l}\text { Formaldehyde, } \\
\text { Acetaldehyde, } \\
\text { Benzene }\end{array}$ & $\begin{array}{l}27600000 \\
(21700000)\end{array}$ & $\begin{array}{c}-0.005 \\
(0.00129)\end{array}$ & $\begin{array}{c}99.9 \% \\
(n=4)\end{array}$ \\
\hline \multirow[t]{2}{*}{ Power plant } & $\begin{array}{l}\text { Boilers (GP01, GP02, } \\
\text { GP03) }\end{array}$ & $\begin{array}{l}\text { Formaldehyde, } \\
\text { Acetaldehyde, } \\
\text { Benzene }\end{array}$ & $\begin{array}{l}755887 \\
(48729)\end{array}$ & $\begin{array}{c}-0.083 \\
(0.0127)\end{array}$ & $\begin{array}{l}99.2 \% \\
(n=3)\end{array}$ \\
\hline & Boiler (GP04) & Nickel, Arsenic & $\begin{array}{l}755887 \\
(48729)\end{array}$ & $\begin{array}{c}-0.083 \\
(0.0127)\end{array}$ & $\begin{array}{l}99.2 \% \\
(n=3)\end{array}$ \\
\hline $\begin{array}{l}\text { Noncellulosic Organic } \\
\text { Fiber Manufacturing }\end{array}$ & $\begin{array}{l}\text { Maelic Anhydride Plant } \\
\text { Process Vent (SO01) }\end{array}$ & $\begin{array}{l}\text { Formaldehyde, } \\
\text { Acetaldehyde, } \\
\text { Benzene }\end{array}$ & $\begin{array}{l}1214368 \\
(551409)\end{array}$ & $\begin{array}{c}-0.066 \\
(0.0134)\end{array}$ & $\begin{array}{l}99.3 \% \\
(n=6)\end{array}$ \\
\hline $\begin{array}{l}\text { Chemical } \\
\text { Manufacturing }\end{array}$ & $\begin{array}{l}\text { Methylamine Plant } \\
\text { Process Vent (AP01) }\end{array}$ & $\begin{array}{l}\text { Formaldehyde, } \\
\text { Acetaldehyde, } \\
\text { Benzene }\end{array}$ & $\begin{array}{l}1214368 \\
(551409)\end{array}$ & $\begin{array}{c}-0.066 \\
(0.0134)\end{array}$ & $\begin{array}{c}99.3 \% \\
(n=6)\end{array}$ \\
\hline $\begin{array}{l}\text { Noncellulosic Organic } \\
\text { Fiber Manufacturing }\end{array}$ & $\begin{array}{l}\text { Fugitive Emissions } \\
\text { (SF01, SF02, SF03) }\end{array}$ & Acrylonitrile & $\begin{array}{c}25600000 \\
(* *)\end{array}$ & $\begin{array}{c}-3.225 \\
(* *)\end{array}$ & $\begin{array}{l}100 \% \\
(n=2)\end{array}$ \\
\hline $\begin{array}{l}\text { Pipeline } \\
\text { Transportation of } \\
\text { Natural Gas }\end{array}$ & Turbine (FG01) & $\begin{array}{l}\text { Formaldehyde, } \\
\text { Acetaldehyde, } \\
\text { Benzene }\end{array}$ & $\begin{array}{c}2248523 \\
(* *)\end{array}$ & $\begin{array}{c}-6.307 \\
(* *)\end{array}$ & $\begin{array}{l}100 \% \\
(n=2)\end{array}$ \\
\hline $\begin{array}{l}\text { Crude Petroleum and } \\
\text { Natural Gas Extraction }\end{array}$ & Turbines (SR01, SR02) & $\begin{array}{l}\text { Formaldehyde, } \\
\text { Acetaldehyde, }\end{array}$ & $\begin{array}{c}2248523 \\
(* *)\end{array}$ & $\begin{array}{c}-6.307 \\
(* *)\end{array}$ & $\begin{array}{l}100 \% \\
(n=2)\end{array}$ \\
\hline
\end{tabular}




\begin{tabular}{|c|c|c|c|c|c|}
\hline \multirow[t]{2}{*}{ Facility type } & \multirow{2}{*}{$\begin{array}{c}\text { Source (ID) } \\
\text { (i) }\end{array}$} & \multirow{2}{*}{$\begin{array}{c}\text { Pollutants } \\
\text { modeled (j) }\end{array}$} & \multicolumn{2}{|c|}{ Parameter estimates* } & \multirow[b]{2}{*}{$\mathbf{R}^{2}$} \\
\hline & & & $a_{i j}$ & $b_{i j}$ & \\
\hline & & Benzene & & & \\
\hline & TEG Reboiler (SR03) & Benzene & $\begin{array}{c}31863 \\
(* *)\end{array}$ & $\begin{array}{c}-0.112 \\
(* *)\end{array}$ & $\begin{array}{l}100 \% \\
(n=2)\end{array}$ \\
\hline
\end{tabular}

* The numbers in the parentheses are standard errors of the estimates

** Standard errors could not be estimated due to very small sample size

Table 3 Optimal Emission Standards for Regulation at Various Spatial Resolutions (Threshold Risk $=$ 1.0E-04; VSL $=\$ 5.5$ Million)

\begin{tabular}{|c|c|c|c|c|c|}
\hline \multirow{2}{*}{$\begin{array}{l}\text { Source } \\
\text { ID } \\
\text { (i) }\end{array}$} & \multirow{2}{*}{$\begin{array}{l}\text { Pollutant } \\
\text { (j) }\end{array}$} & \multirow{2}{*}{$\begin{array}{l}\begin{array}{l}\text { Baseline } \\
\text { emissions }\end{array} \\
Q_{i j}^{b} \text { (TPY) }\end{array}$} & \multicolumn{3}{|c|}{ Optimal emission standards, $Q_{i j}^{*}$ (TPY) } \\
\hline & & & Tract & Block group & Block \\
\hline IP01 & Acetaldehyde & 5.5 & 149.6 & $149.6 \leftrightarrow$ & $196.4 \uparrow$ \\
\hline \multirow[t]{3}{*}{ IP02 } & Formaldehyde & 8.5 & 0 & 0 & 0 \\
\hline & Acetaldehyde & 50.9 & 135.1 & $135.1 \leftrightarrow$ & $69.3 \downarrow$ \\
\hline & Benzene & 5.08 & 0 & 0 & 0 \\
\hline \multirow[t]{3}{*}{ SO01 } & Formaldehyde & 0.0436 & 1.57 & $1.57 \leftrightarrow$ & $7.87 \uparrow$ \\
\hline & Acetaldehyde & 0.00575 & 28.6 & $28.6 \leftrightarrow$ & $34.9 \uparrow$ \\
\hline & Benzene & 0.00052 & 9.35 & $9.35 \leftrightarrow$ & $15.6 \uparrow$ \\
\hline SF01 & Acrylonitrile & 2.819 & 0.11 & $0.11 \leftrightarrow$ & $0.03 \downarrow$ \\
\hline SF02 & Acrylonitrile & 5.48 & 0.28 & $0.28 \leftrightarrow$ & $0.21 \downarrow$ \\
\hline SF03 & Acrylonitrile & 1.159 & 0.17 & $0.17 \leftrightarrow$ & $0.07 \downarrow$ \\
\hline \multirow[t]{3}{*}{ AP01 } & Formaldehyde & 0.869 & 0 & $0 \leftrightarrow$ & 0 \\
\hline & Acetaldehyde & 0.073 & 4.25 & $4.25 \leftrightarrow$ & $10.7 \uparrow$ \\
\hline & Benzene & 0.03 & 0 & 0 & 0 \\
\hline \multirow[t]{3}{*}{ SR01 } & Formaldehyde & 30.52 & 1.02 & $1.02 \leftrightarrow$ & $1.07 \uparrow$ \\
\hline & Acetaldehyde & 2.561 & 1.30 & $1.30 \leftrightarrow$ & $1.35 \uparrow$ \\
\hline & Benzene & 1.0405 & 1.10 & $1.10 \leftrightarrow$ & $1.15 \uparrow$ \\
\hline \multirow[t]{3}{*}{ SR02 } & Formaldehyde & 0.01027 & 1.06 & $1.06 \leftrightarrow$ & $1.11 \uparrow$ \\
\hline & Acetaldehyde & 0.00135 & 1.34 & $1.34 \leftrightarrow$ & $1.39 \uparrow$ \\
\hline & Benzene & 0.000123 & 1.14 & $1.14 \leftrightarrow$ & $1.19 \uparrow$ \\
\hline SR03 & Benzene & 1.3 & 0 & 0 & 0 \\
\hline
\end{tabular}




\begin{tabular}{|c|c|c|c|c|c|}
\hline \multirow{2}{*}{$\begin{array}{l}\text { Source } \\
\text { ID } \\
\text { (i) }\end{array}$} & \multirow{2}{*}{$\begin{array}{l}\text { Pollutant } \\
\text { (j) }\end{array}$} & \multirow{2}{*}{$\begin{array}{l}\begin{array}{l}\text { Baseline } \\
\text { emissions }\end{array} \\
Q_{i j}^{b} \text { (TPY) }\end{array}$} & \multicolumn{3}{|c|}{ Optimal emission standards, $Q_{i j}^{*}$ (TPY) } \\
\hline & & & Tract & Block group & Block \\
\hline \multirow[t]{3}{*}{ FG01 } & Formaldehyde & 78.8 & 1.15 & $1.15 \leftrightarrow$ & $1.20 \uparrow$ \\
\hline & Acetaldehyde & 6.615 & 1.43 & $1.43 \leftrightarrow$ & $1.48 \uparrow$ \\
\hline & Benzene & 2.687 & 1.23 & $1.23 \leftrightarrow$ & $1.28 \uparrow$ \\
\hline \multirow[t]{3}{*}{ GP01 } & Formaldehyde & 0.031 & 14.9 & $14.9 \leftrightarrow$ & $18.4 \uparrow$ \\
\hline & Acetaldehyde & 0.000006 & 36.3 & $36.3 \leftrightarrow$ & $39.8 \uparrow$ \\
\hline & Benzene & 0.00087 & 21.1 & $21.1 \leftrightarrow$ & $24.5 \uparrow$ \\
\hline \multirow[t]{3}{*}{ GP02 } & Formaldehyde & 0.00098 & 24.2 & $24.2 \leftrightarrow$ & $27.0 \uparrow$ \\
\hline & Acetaldehyde & 0.0000002 & 45.6 & $45.6 \leftrightarrow$ & $48.4 \uparrow$ \\
\hline & Benzene & 0.000028 & 30.4 & $30.4 \leftrightarrow$ & $33.1 \uparrow$ \\
\hline \multirow[t]{3}{*}{ GP03 } & Formaldehyde & 0.00228 & 37.8 & $37.8 \leftrightarrow$ & $40.2 \uparrow$ \\
\hline & Acetaldehyde & 0.0000004 & 59.2 & $59.2 \leftrightarrow$ & $61.6 \uparrow$ \\
\hline & Benzene & 0.0000621 & 44.0 & $44.0 \leftrightarrow$ & $46.4 \uparrow$ \\
\hline \multirow[t]{2}{*}{ GP04 } & Nickel & 0.4095 & 0 & 0 & 0 \\
\hline & Arsenic & 0.438 & 0 & 0 & 0 \\
\hline & $\begin{array}{l}\text { Net Costs } \\
\text { (Million \$/y) }\end{array}$ & & 17.76 & 17.76 & 35.47 \\
\hline
\end{tabular}

Note: $\uparrow$ - Increase in optimal emissions; $\downarrow$ - Decrease in optimal emissions; $\leftrightarrow$ - No change in optimal emissions 
Table 4a. Hot Spot Locations and Change in Optimal Emissions with Change in Spatial Resolution (Tract to Block Group Resolution; Risk Threshold: 100 in a Million)

\begin{tabular}{|c|c|c|c|c|c|c|c|c|c|}
\hline $\begin{array}{l}\text { Location No. } \\
\text { (k) }\end{array}$ & $\begin{array}{c}\lambda_{k} \\
\text { (Tract) } \\
(K=77)\end{array}$ & $\begin{array}{c}\lambda_{k}^{\prime} \\
\text { (Block } \\
\text { Group) } \\
(\mathrm{K}=319)\end{array}$ & \multicolumn{7}{|c|}{$\beta_{i j k}\left(\mu g / m^{3}\right)$} \\
\hline 16 & $1.1 \mathrm{E}+11$ & $1.1 \mathrm{E}+11$ & 0.2769 & 0.0219 & 0.0084 & 0.0019 & 0.0031 & 0.0062 & 0.007 \\
\hline 17 & $2.5 \mathrm{E}+11$ & $2.5 \mathrm{E}+11$ & 0.0024 & 0.0087 & 0.1047 & 0.0022 & 0.0055 & 3.399 & 0.0024 \\
\hline \multicolumn{10}{|c|}{ Optimal Emissions (TPY) } \\
\hline Tract & & & 135 & 28.6 & 4.2 & 1.4 & 1.3 & 0.11 & 36.3 \\
\hline BG & & & 135 & 28.6 & 4.2 & 1.4 & 1.3 & 0.11 & 36.3 \\
\hline
\end{tabular}

Table 4b. Hot Spot Locations and Change in Optimal Emissions with Change in Spatial Resolution (Block Group to Block Resolution; Risk Threshold: 100 in a Million)

\begin{tabular}{|c|c|c|c|c|c|c|c|c|c|}
\hline $\begin{array}{l}\text { Location No. } \\
\text { (k) }\end{array}$ & $\begin{array}{c}\lambda_{k} \\
\text { (Block } \\
\text { Group) } \\
(\mathrm{K}=319)\end{array}$ & $\begin{array}{c}\lambda_{k}^{\prime} \\
\text { (Block) } \\
(\mathrm{K}=9881)\end{array}$ & \multicolumn{7}{|c|}{$\beta_{i j k}\left(\mu g / m^{3}\right)$} \\
\hline 16 & $1.1 \mathrm{E}+11$ & 0 & 0.2769 & 0.0219 & 0.0084 & 0.0019 & 0.0031 & 0.0062 & 0.007 \\
\hline 17 & $2.5 \mathrm{E}+11$ & 0 & 0.0024 & 0.0087 & 0.1047 & 0.0022 & 0.0055 & 3.399 & 0.0024 \\
\hline 2503 & - & $1.7 \mathrm{E}+11$ & 0.0024 & 0.008 & 0.1007 & 0.0226 & 0.056 & 6.411 & 0.0024 \\
\hline 9361 & - & $0.85 \mathrm{E}+11$ & 0.5218 & 0.0265 & 0.0077 & 0.0019 & 0.0036 & 0.0059 & 0.0075 \\
\hline \multicolumn{10}{|c|}{ Optimal Emissions (TPY) } \\
\hline BG & & & 135 & 28.6 & 4.2 & 1.4 & 1.3 & 0.11 & 36.3 \\
\hline Block & & & 69.2 & 34.9 & 10.7 & 1.5 & 1.35 & 0.03 & 39.8 \\
\hline
\end{tabular}

All emissions are for the pollutant acetaldehyde, except for SF01 for which the pollutant is acrylonitrile

In table 4a, the optimal emissions are identical at both tract and block group (BG) resolution regulation because there are no new hot spots captured at the finer BG resolution. In table 4b, location \# 2503 and 9361 are the new hot spots captured at the finer block resolution regulation ( $\lambda_{k}^{\prime}>0$ ). Since IP02 (with $\beta=0.5218$ ) contributes most to the risk at the new hot spot 9361, its optimal emissions are lower at the finer block resolution. Because of similar reasoning, the optimal emissions are lower for SF01 at the finer resolution. 
Table 5 Percent Change in Abatement Costs Due to Regulation at Finer Spatial Resolution

\begin{tabular}{|l|r|r|r|}
\hline \multirow{2}{*}{$\begin{array}{l}\text { Source } \\
\text { ID }\end{array}$} & \multicolumn{3}{|c|}{$\begin{array}{l}\text { Percent change in abatement costs due to regulation at } \\
\text { census block resolution instead of tract resolution (\$)* }\end{array}$} \\
\cline { 2 - 4 } & $\mathbf{3}$ Risk Threshold \\
\cline { 2 - 4 } & $\mathbf{1 0 0}$ in a Million & $\mathbf{1 0}$ in a Million & 1 in a Million \\
\hline IP01 & $-3.8 \%$ & $4.9 \%$ & $33.5 \%$ \\
\hline IP02 & $99 \%$ & $0 \%$ & $0 \%$ \\
\hline SF01 & $-38.6 \%$ & $3.4 \%$ & $0 \%$ \\
\hline SF02 & $29.4 \%$ & $0 \%$ & $0 \%$ \\
\hline SF03 & $25.3 \%$ & $10.2 \%$ & $3.3 \%$ \\
\hline AP01 & $39.7 \%$ & $0 \%$ & $0 \%$ \\
\hline SR01 & $-143 \%$ & $-56 \%$ & $0.5 \%$ \\
\hline SR02 & $-53 \%$ & $44 \%$ & $10.1 \%$ \\
\hline SR03 & $-0.02 \%$ & $0 \%$ & $0 \%$ \\
\hline FG01 & $0 \%$ & $0 \%$ & $2730 \% * *$ \\
\hline GP01 & $-27 \%$ & $-17.7 \%$ & $-15.5 \%$ \\
\hline GP02 & $-5.2 \%$ & $14.9 \%$ & $0.05 \%$ \\
\hline GP03 & $-1.7 \%$ & $3.7 \%$ & $7.55 \%$ \\
\hline GP04 & $-0.5 \%$ & $0.8 \%$ & $0 \%$ \\
\hline * Negative values indicate lower abatement costs and positive values indicate higher abatement
\end{tabular}

* Negative values indicate lower abatement costs and positive values indicate higher abatement costs at finer resolution relative to coarse resolution

** This change is so large because this source has a really steep marginal abatement cost function and as the optimal emissions approach zero at block resolution, the cost increases dramatically between block and tract resolutions. 

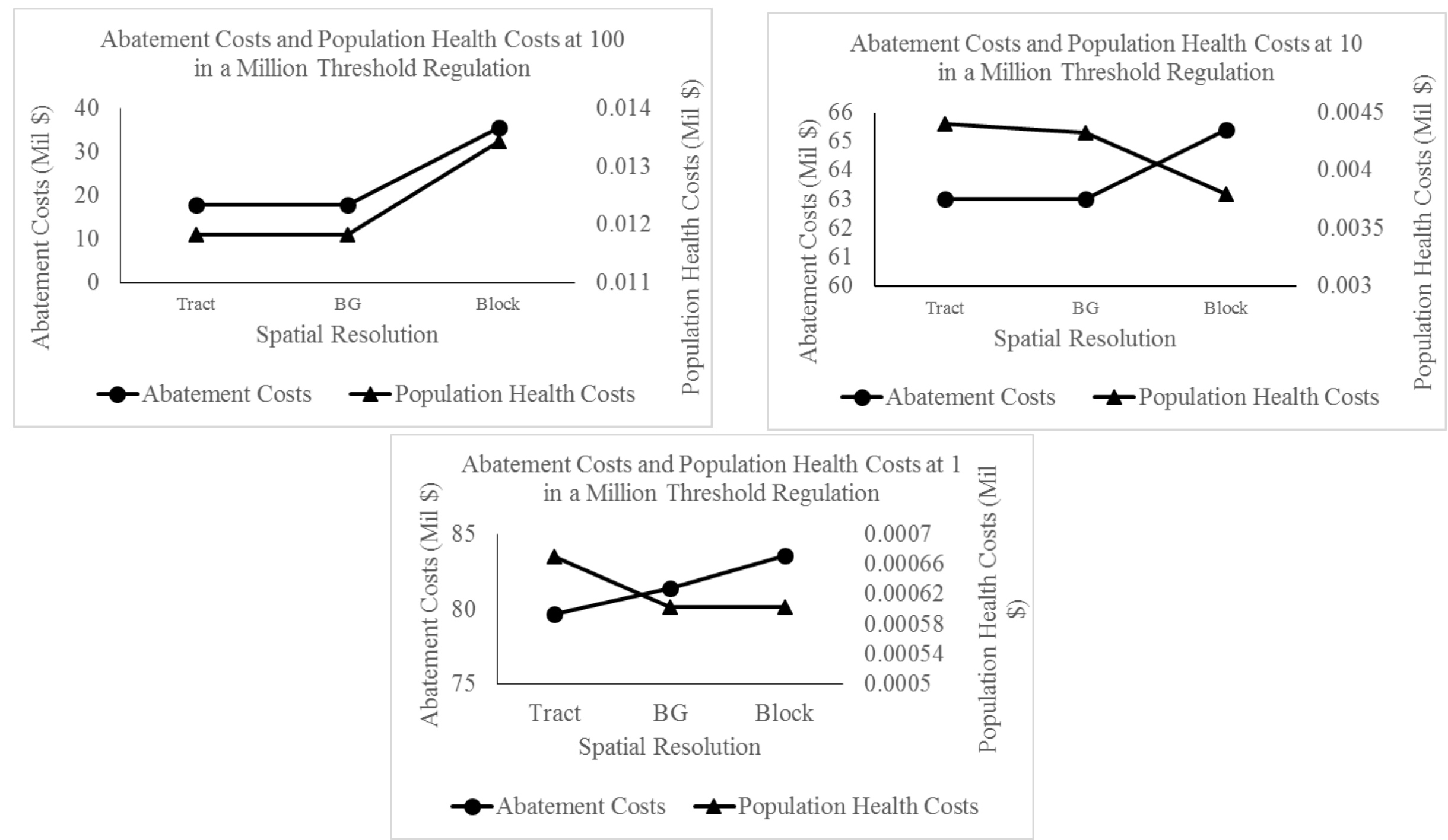

Figure 1. Variation of Abatement and Population Health Costs with Spatial Resolution 


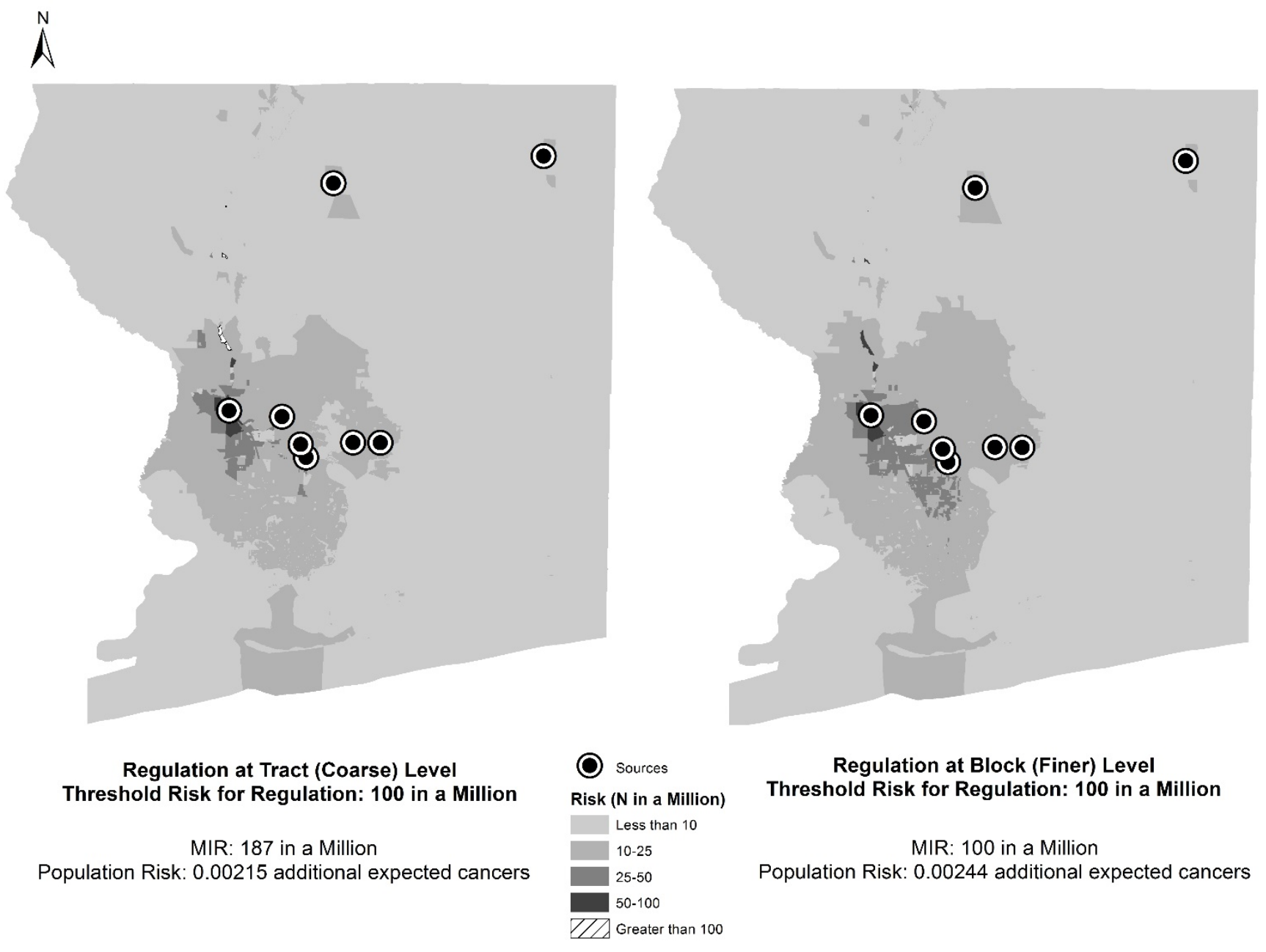

Figure 2 Spatial Distribution of Cancer Risks in Escambia and Santa Rosa Counties at a Risk Threshold of 100 in a Million The left and right panels show the cancer risk distribution under the coarse (tract) and finer (block) regulation respectively. The panels also show the maximum individual risk (MIR) and population risks that would result under the two resolutions of regulation. 

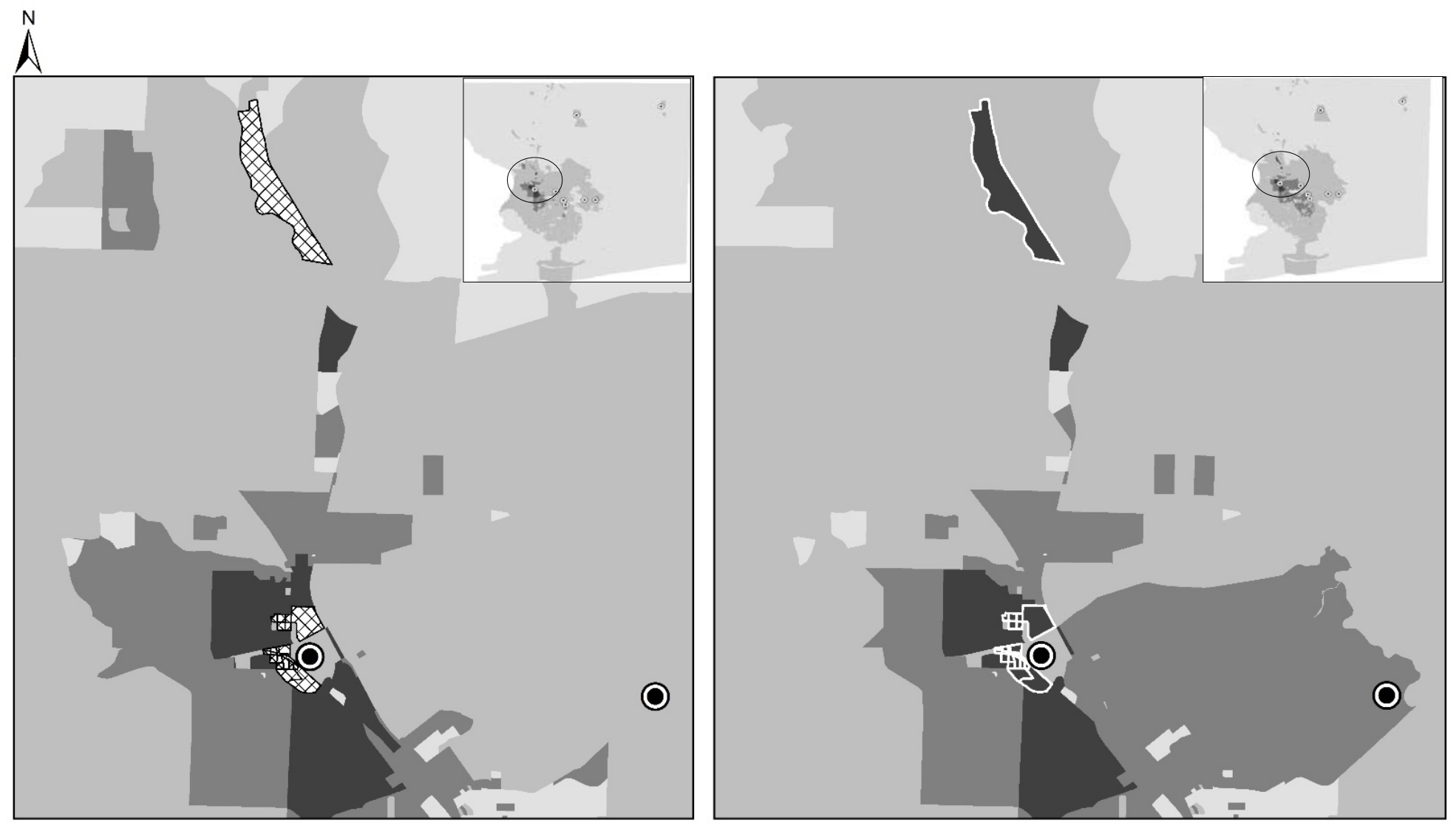

Sources

Regulation at Tract (Coarse) Level Risk (N in a Million)

Less than 10 Threshold Risk for Regulation: 100 in a Million

$10-25$
$25-50$
$50-100$

Regulation at Block (Finer) Level Threshold Risk for Regulation: 100 in a Million

Figure 3 Map Depicting Reduction in MIR at Finer Resolution Regulation (Risk Threshold: 100 in a Million) The two panels zoom in on the same region (the circled areas in the respective inset maps) within the study area, showing risk distributions under the coarse tract regulation (left panel) and the finer block regulation (right panel). The hatched regions in the left panel show hot spots that would go unregulated under the coarse regulation. The same regions are shown with a white outline in the right panel to highlight that the risk at these hot spots reduces to below the threshold level of 100 in a million under the finer regulation. 


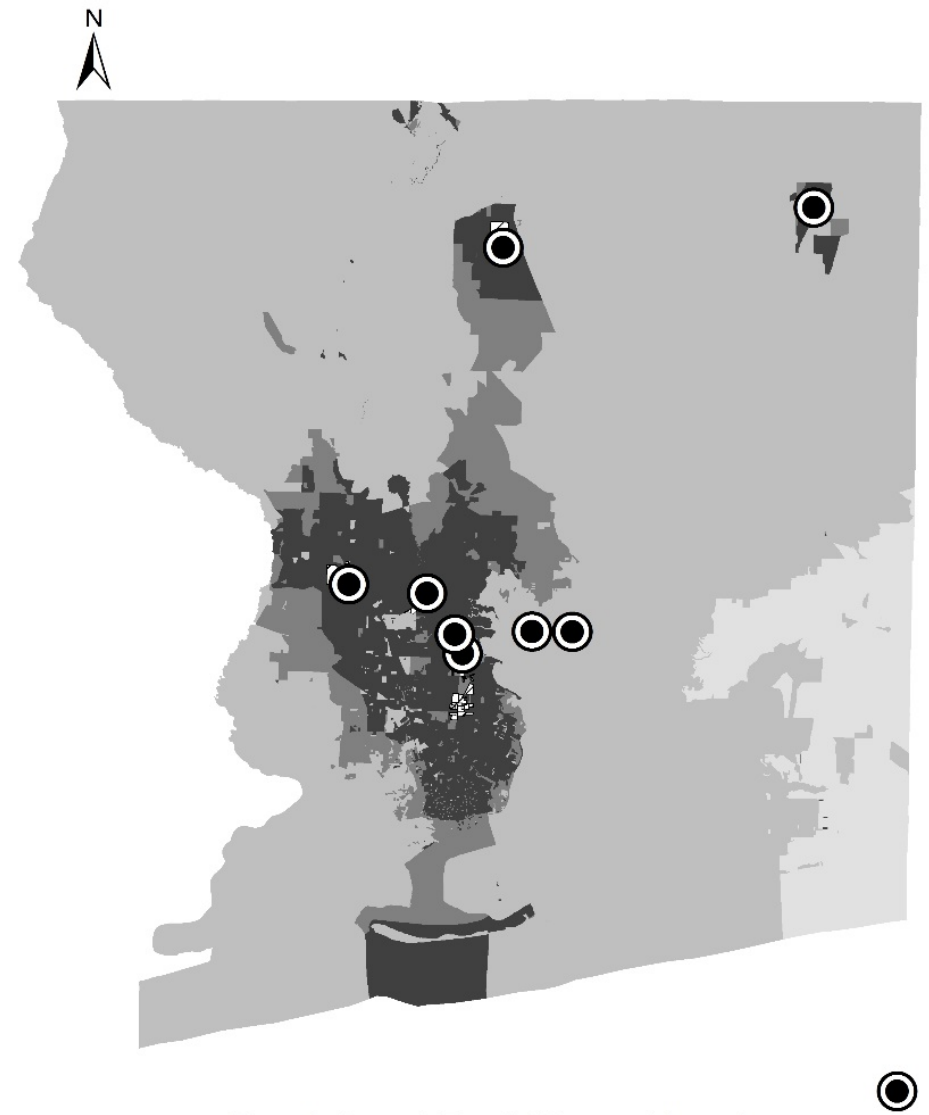

Regulation at Tract (Coarse) Level Threshold Risk for Regulation: 10 in a Million MIR: 17 in a Million Population Risk: 0.0008 additional expected cancers
Sources Risk (N in a Million) Less than 1

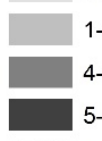

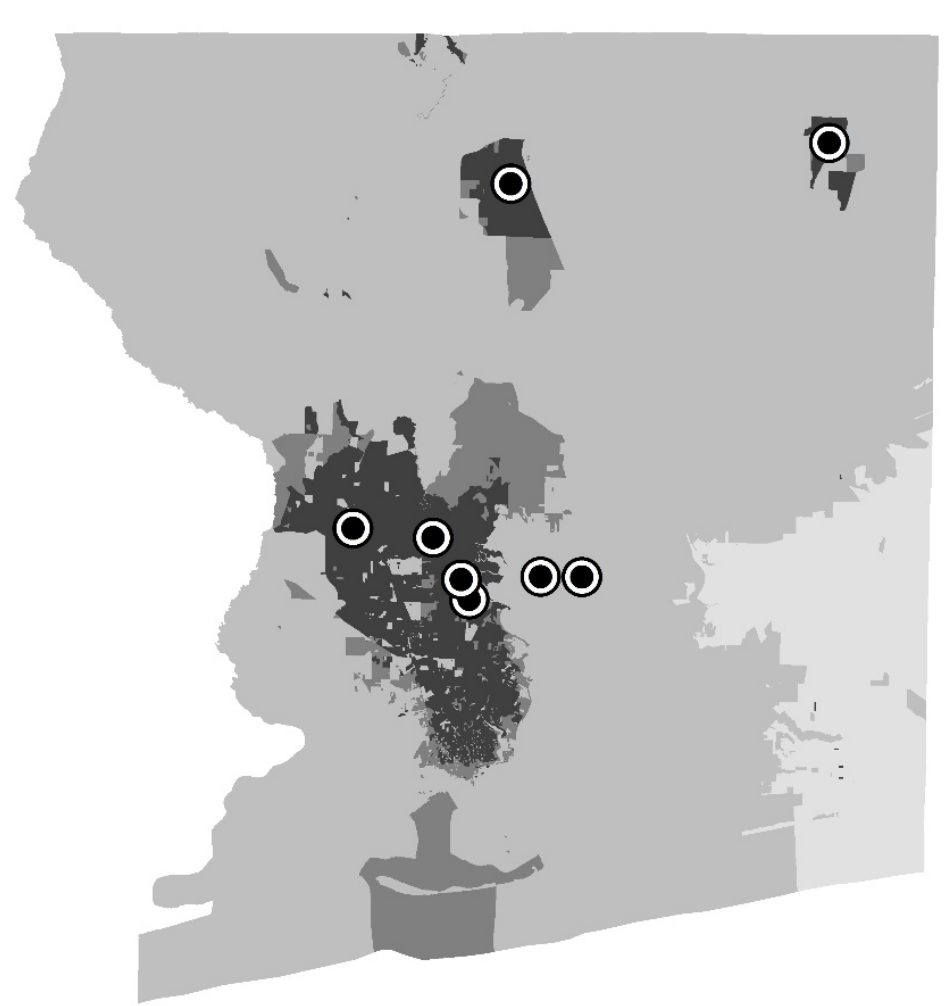

Regulation at Block (Finer) Level Threshold Risk for Regulation: 10 in a Million

MIR: 10 in a Million

Population Risk: 0.00689 additional expected cancers

Figure 4 Spatial Distribution of Cancer Risks in Escambia and Santa Rosa Counties at a Risk Threshold of 10 in a Million The left and right panels show the cancer risk distribution under the coarse (tract) and finer (block) regulation respectively. The panels also show the maximum individual risk (MIR) and population risks that would result under the two resolutions of regulation. 

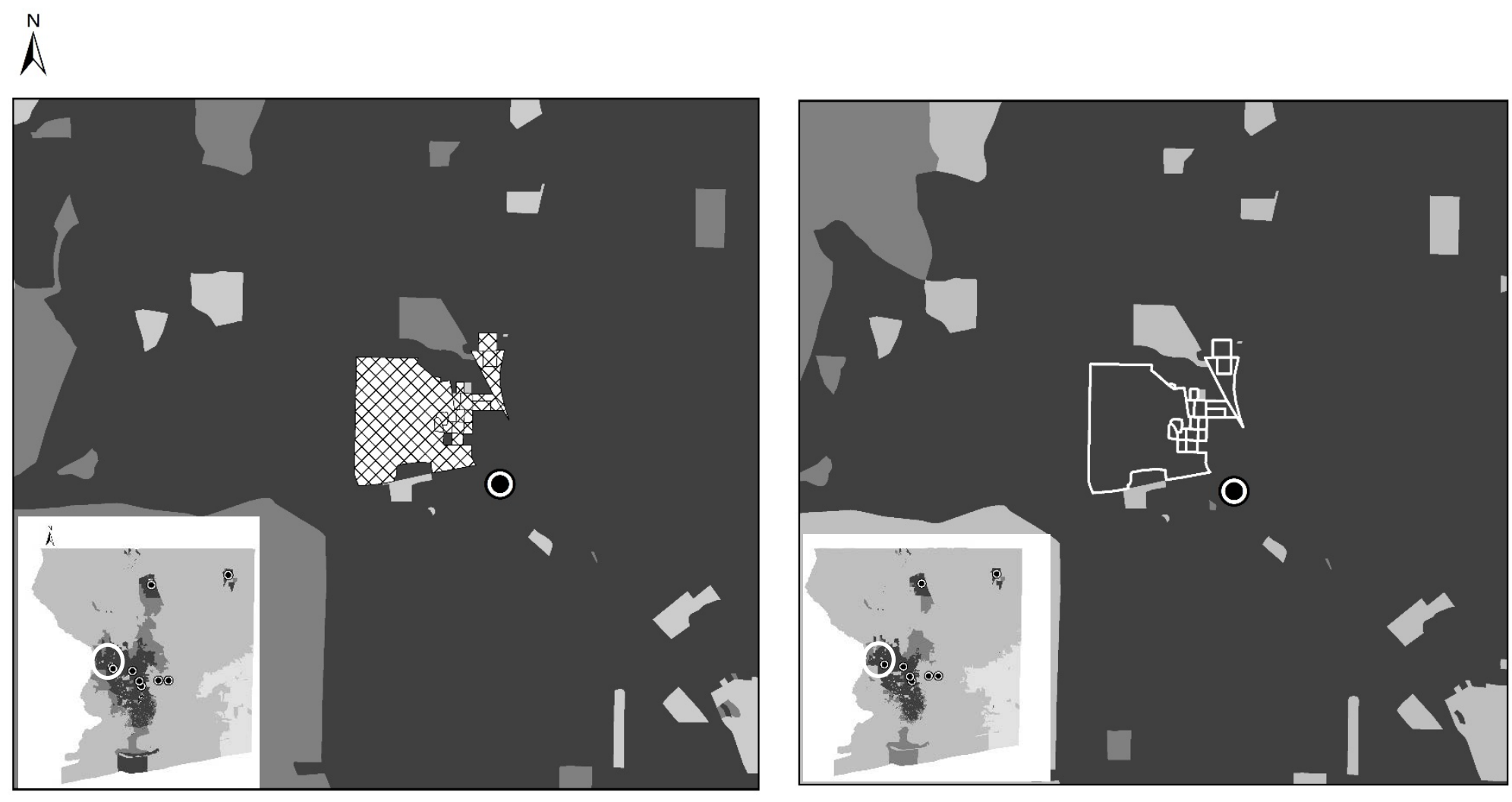

Regulation at Tract (Coarse) Level

O) Sources

Risk (N in a Million)

Less than $1 \quad$ Regulation at Block (Finer) Level Threshold Risk for Regulation: 10 in a Million

$1-4$

Threshold Risk for Regulation: 10 in a Million

5-10

$X$ Greater than 10

Figure 5 Map Depicting Reduction in MIR at Finer Resolution Regulation (Risk Threshold: 10 in a Million)

The two panels zoom in on the same region (the circled areas in the respective inset maps) within the study area, showing risk distributions under the coarse tract regulation (left panel) and the finer block regulation (right panel). The hatched regions in the left panel show hot spots that would go unregulated under the coarse regulation. The same regions are shown with a white outline in the right panel to highlight that the risk at these hot spots reduces to below the threshold level of 10 in a million under the finer regulation 


\section{APPENDIX: KUHN-TUCKER CONDITIONS}

The decisionmaker's problem is:

$\operatorname{Min}_{Q_{i j}}\left\{\left(\sum_{i=1}^{I} \sum_{j=1}^{J} \int_{Q_{i j}}^{Q_{i j}} M A C_{i j}\left(q_{i j}\right) \cdot d q_{i j}\right)+\left(\sum_{i=1}^{I} \sum_{j=1}^{J} \sum_{m=1}^{M} Q_{i j} \beta_{i j m} u_{j} V\right)\right\}$

Subject to the constraints:

$\sum_{i=1}^{I} \sum_{j=1}^{J} Q_{i j} \beta_{i j k} u_{j} \leq \bar{r} \quad \forall k=1,2,3, \ldots ., K$

$Q_{i j} \geq 0$

Applying the Kuhn-Tucker formulation, the Lagrangian will be:

$$
\begin{aligned}
& L=-\sum_{i=1}^{I} \sum_{j=1}^{J} \int_{Q_{i j}}^{Q_{i j}^{b}} M A C_{i j}\left(q_{i j}\right) \cdot d q_{i j}-\sum_{i=1}^{I} \sum_{j=1}^{J} \sum_{m=1}^{M} Q_{i j} \beta_{i j m} u_{j} V \\
& -\lambda_{1}\left(\sum_{i=1}^{I} \sum_{j=1}^{J} Q_{i j} \beta_{i j 1} u_{j}-\bar{r}\right)-\ldots .-\lambda_{K}\left(\sum_{i=1}^{I} \sum_{j=1}^{J} Q_{i j} \beta_{i j K} u_{j}-\bar{r}\right)
\end{aligned}
$$

The first order conditions will be:

$$
\begin{gathered}
\frac{\partial L}{\partial Q_{i j}}=M A C_{i j}\left(Q_{i j}^{*}\right)-\sum_{m=1}^{M} \beta_{i j m} u_{j} V-\sum_{k=1}^{K} \lambda_{k} \beta_{i j k} u_{j} \leq 0 \\
Q_{i j} \frac{\partial L}{\partial Q_{i j}}=Q_{i j}^{*} M A C_{i j}\left(Q_{i j}^{*}\right)-\sum_{m=1}^{M} Q_{i j}^{*} \beta_{i j m} u_{j} V-\sum_{k=1}^{K} \lambda_{k} Q_{i j}^{*} \beta_{i j k} u_{j}=0 \\
\frac{\partial L}{\partial \lambda_{1}}=-\left(\sum_{i=1}^{I} \sum_{j=1}^{J} Q_{i j}^{*} \beta_{i j} u_{j}-\bar{r}\right) \geq 0, \ldots, \frac{\partial L}{\partial \lambda_{K}}=-\left(\sum_{i=1}^{I} \sum_{j=1}^{J} Q_{i j}^{*} \beta_{i j K} u_{j}-\bar{r}\right) \geq 0 \\
\lambda_{k} \frac{\partial L}{\partial \lambda_{K}}=-\lambda_{k}\left(\sum_{i=1}^{I} \sum_{j=1}^{J} Q_{i j}^{*} \beta_{i j k} u_{j}-\bar{r}\right)=0 \forall \mathrm{k}=1,2,3, \ldots ., \mathrm{K} \\
\lambda_{1} \geq 0, \ldots . . \lambda_{K} \geq 0
\end{gathered}
$$


The emission quantities are assumed non-negative. Given this, the condition in equation (A.5) holds with equality. It can thus be written as:

$$
-M A C_{i j}\left(Q_{i j}^{*}\right)+\sum_{m=1}^{M} \beta_{i j m} u_{j} V+\sum_{k=1}^{K} \lambda_{k} \beta_{i j k} u_{j}=0
$$

\section{REFERENCES}

Adler, M. D. (2005). Against" Individual Risk": A Sympathetic Critique of Risk Assessment. University of Pennsylvania Law Review, 153(4), 1121-1250.

Bae, C., Sandlin, G., Bassok, A., \& Kim, S. (2007). The exposure of disadvantaged populations in freeway air-pollution sheds: a case study of the Seattle and Portland regions. Environment and Planning B, 34(1), 154.

Burtraw, D., Evans, D. A., Krupnick, A., Palmer, K., \& Toth, R. (2005). Economics of Pollution Trading for $\mathrm{SO}_{2}$ and $\mathrm{NO}_{x}$. Annu. Rev. Environ. Resour., 30, 253-289.

Carlson, C., Burtraw, D., Cropper, M., \& Palmer, K. L. (2000). Sulfur Dioxide Control by Electric Utilities: What Are the Gains from Trade? Journal of Political Economy, 108(6), 1292-1326.

Dolinoy, D. C., \& Miranda, M. L. (2004). GIS Modeling of Air Toxics Releases from TRIReporting and Non-TRI-Reporting Facilities: Impacts for Environmental Justice. Environmental Health Perspectives, 112(17), 1717-1724.

E.P.A. (1999a). The Benefits and Costs of the Clean Air Act, 1990 to 2010 (No. EPA-410-R-99001). Washington, DC: U.S. Environmnetal Protection Agency.Accessed from on E.P.A. (1999b). Residual Risk Report to Congress (No. EPA-453/R-99-001). Research Triangle Park, NC: US Environmental Protection Agency.Accessed from on 
E.P.A. (2001). Workplan for the National Air Toxics Program and Integrated Air Toxics State/local/tribal Program Structure: Emission Standards Division, Office of Air Quality Planning and Standards.Accessed from on

E.P.A. (2003). International Analysis of Methane and Nitrous Oxide Abatement Opportunities: Report to Energy Modeling Forum.Accessed from http://www.epa.gov/climatechange/economics/pdfs/methodologych4.pdf on 18 February 2011

E.P.A. (2004). National Monitoring Strategy: Air Toxics Component. Research Triangle Park, NC: U.S. Environmental Protection Agency.Accessed from on

E.P.A. (2006a). Air Toxics Risk Assessment Reference Library, Volume 3: Community-Scale Assessment (No. EPA-452/K-06-001C). Research Triangle Park, NC: U.S. Environmental Protection Agency.Accessed from on

E.P.A. (2006b). RAIMI - Regional Air Impact Modeling Initiative. Retrieved 12 March 2006, from http://www.epa.gov/region06/6en/raimi/index.htm

E.P.A. (2008). Ambient Air Monitoring Strategy for State, Local, and Tribal Air Agencies Office of Air Quality Planning and Standards, Research Triangle Park, NC Accessed from http://www.epa.gov/ttnamti1/files/ambient/monitorstrat/AAMS\%20for\%20SLTs\%20\%2 0-\%20FINAL\%20Dec\%202008.pdf on

E.P.A. (2013). Integrated Risk Information System (IRIS), from http://www.epa.gov/iris/index.html, accessed on 8 June 2013

Fowlie, M., Holland, S. P., \& Mansur, E. T. (2012). What Do Emissions Markets Deliver and to Whom? Evidence from Southern California's NOx Trading Program. The American Economic Review, 102(2), 965-993. 
Goldstein, B. D. (1995). The need to restore the public health base for environmental control. American Journal of Public Health, 85(4), 481-483.

Graham, J. D. (2007). The Evolving Regulatory Role of the US Office of Management and Budget. Review of Environmental Economics and Policy, 1(2), 171-191.

Hamilton, J. T., \& Viscusi, W. K. (1999). How costly is “clean”? An analysis of the benefits and costs of Superfund site remediations. Journal of Policy Analysis and Management, 18(1), $2-27$.

Hammitt, J. K. (2000). Valuing mortality risk: theory and practice. Environmental Science \& Technology, 34(8), 1396-1400.

Hanemann, M. (2008). California's new greenhouse gas laws. Review of Environmental Economics and Policy, 2(1), 114-129.

Hartman, R. S., Wheeler, D., \& Singh, M. (1997). The cost of air pollution abatement. Applied Economics, 29(6), 759-774.

Henry, D. D., Muller, N. Z., \& Mendelsohn, R. O. (2011). The social cost of trading: Measuring the increased damages from sulfur dioxide trading in the United States. Journal of Policy Analysis and Management, 30(3), 598-612.

Kanaroglou, P. S., Jerrett, M., Morrison, J., Beckerman, B., Arain, M. A., Gilbert, N. L., et al. (2005). Establishing an air pollution monitoring network for intra-urban population exposure assessment: A location-allocation approach. Atmospheric Environment, 39(13), 2399-2409.

Karvosenoja, N., \& Johansson, M. (2003). Cost curve analysis for SO2 and NOx emission control in Finland. Environmental Science \& Policy, 6(4), 329-340. 
Kilmont, Z., Amann, M., \& Cofala, J. (2000). Estimating costs for controlling emissions of volatile organic compounds (VOC) from stationary sources. (No. Interim Report No. IR00-51): International Institute for Applied Systems Analysis, Austria.Accessed from http://www.iiasa.ac.at/Admin/PUB/Documents/IR-00-051.pdf on 18 February 2011

Kopp, R., Krupnick, A., \& Toman, M. (1997). Cost-Benefit Analysis and Regulatory Reform: An Assessment of the Science and the Art (No. Discussion Paper 97-19). Washington, D.C.: Resources for the Future.Accessed from on

Kumar, A., Bellam, N. K., \& Sud, A. (1999). Performance of an industrial source complex model: Predicting long-term concentrations in an urban area. Environmental Progress, 18(2), 93-100.

Kumar, N. (2009). An optimal spatial sampling design for intra-urban population exposure assessment. Atmospheric Environment, 43(5), 1153-1155.

Levy, J. I., \& Hanna, S. R. (2011). Spatial and temporal variability in urban fine particulate matter concentrations. Environmental Pollution, 159(8), 2009-2015.

Lorber, M., Eschenroeder, A., \& Robinson, R. (2000). Testing the USA EPA's ISCST-Version 3 model on dioxins: a comparison of predicted and observed air and soil concentrations. Atmospheric Environment, 34(23), 3995-4010.

Mariam, Y., \& Barre, M. (1996). VOCs Cost functions in the Design of Emission Abatement Strategies (No. Munich Personal RePEc Archive (MPRA) Paper No. 658). Munich: Munich University Library.Accessed from http://mpra.ub.uni-muenchen.de/658/ on

Mrozek, J. R., \& Taylor, L. O. (2002). What Determines the Value of Life? A Meta-Analysis. Journal of Policy Analysis and Management, 18. 
NRC. (2004). Air quality management in the United States. Washington, D.C.: National Academies Press.

Pastor, M., Morello-Frosch, R., \& Sadd, J. L. (2006). Breathless: schools, air toxics, and environmental justice in California. Policy Studies Journal, 34(3), 337-362.

Pervin, T., Gerdtham, U. G., \& Lyttkens, C. H. (2008). Societal costs of air pollution-related health hazards: A review of methods and results. Cost Effectiveness and Resource Allocation, 6(1), 19.

Pratt, G. C., Wu, C. Y., Bock, D., Adgate, J. L., Ramachandran, G., Stock, T. H., et al. (2004). Comparing Air Dispersion Model Predictions with Measured Concentrations of VOCs in Urban Communities. Environmental Science \& Technology, 38(7), 1949-1959.

Rabl, A., Spadaro, J. V., \& Van Der Zwaan, B. (2005). Uncertainty of air pollution cost estimates: to what extent does it matter? Environ. Sci. Technol, 39(2), 399-408.

Rezek, J. O. N., \& Blair, B. F. (2005). Abatement Cost Heterogeneity in Phase I electric utilties. Contemporary Economic Policy, 23(3), 324-340.

Ringquist, E. J. (2005). Assessing evidence of environmental inequities: A meta-analysis. Journal of Policy Analysis and Management, 24(2), 223-247.

Ringquist, E. J. (2011). Trading Equity for Efficiency in Environmental Protection? Environmental Justice Effects from the SO2 Allowance Trading Program*. Social Science Quarterly, 92(2), 297-323.

Rousseau, S., \& Proost, S. (2005). Comparing environmental policy instruments in the presence of imperfect compliance-A case study. Environmental and Resource Economics, 32(3), 337-365. 
Sivacoumar, R., Bhanarkar, A. D., Goyal, S. K., Gadkari, S. K., \& Aggarwal, A. L. (2001). Air pollution modeling for an industrial complex and model performance evaluation. Environmental Pollution, 111(3), 471-477.

Strategic Toxic Air Reduction Program. (2013). Retrieved 27 May 2013, from http://www.louisvilleky.gov/apcd/star/

Su, J. G., Larson, T., Baribeau, A. M., Brauer, M., Rensing, M., \& Buzzelli, M. (2007). Spatial Modeling for Air Pollution Monitoring Network Design: Example of Residential Woodsmoke. Journal of the Air \& Waste Management Association, 57(8), 893-900.

Touma, J. S., Cox, W. M., \& Tikvart, J. A. (2006). Spatial and temporal variability of ambient air toxics data. Journal of the Air \& Waste Management Association, 56(12), 1716-1725.

UWF. (2011). Partnership for Environmental Research and Community Health (PERCH). Retrieved 11 February 2011, from http://uwf.edu/cedb/perch.cfm

Van Houtven, G., \& Cropper, M. L. (1996). When is a life too costly to save? The evidence from US environmental regulations. Journal of Environmental Economics and Management, 30(3), 348-368.

Viscusi, W. K., \& Aldy, J. E. (2003). The Value of a Statistical Life: A Critical Review of Market Estimates Throughout the World. Journal of Risk and Uncertainty, 27(1), 5-76. 